\title{
Deep Vadose Zone Treatability Test for the Hanford Central Plateau: Interim Post-Desiccation Monitoring Results
}

\author{
MJ Truex \\ M Oostrom \\ CE Strickland \\ TC Johnson \\ CD Johnson \\ RE Clayton \\ GB Chronister
}

September 2013

Pacific Northwest

NATIONAL LABORATORY

Proudly Operated by Battelle Since 1965 


\title{
DISCLAIMER
}

This report was prepared as an account of work sponsored by an agency of the United States Government. Neither the United States Government nor any agency thereof, nor Battelle Memorial Institute, nor any of their employees, makes any warranty, express or implied, or assumes any legal liability or responsibility for the accuracy, completeness, or usefulness of any information, apparatus, product, or process disclosed, or represents that its use would not inf ringe privately owned rights. Reference herein to any specific commercial product, process, or service by trade name, trademark, manufacturer, or otherwise does not necessarily constitute or imply its endorsement, recommendation, or favoring by the United States Government or any agency thereof, or Battelle Memorial Institute. The views and opinions of authors expressed herein do not necessarily state or reflect those of the United States Government or any agency thereof.

\author{
PACIFIC NORTHWEST NATIONAL LABORATORY \\ operated by \\ BATTELLE \\ for the \\ UNITED STATES DEPARTMENT OF ENERGY \\ under Contract DE-AC05-76RL01830
}

Printed in the United States of America
Available to DOE and DOE contractors from the
Office of Scientific and Technical Information
P.O. Box 62, Oak Ridge, TN 37831-0062;
ph: (865) 576-8401
fax: $(865) 576-5728$
email: reports@adonis.osti.gov

Available to the public from the National Technical Information Service

5301 Shawnee Rd., Alexandria, VA 22312

ph: (800) 553-NTIS (6847)

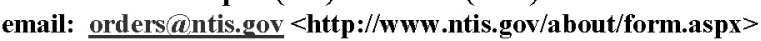

Online ordering: http://www.ntis.gov

This document was printed on recycled paper. 


\title{
Deep Vadose Zone Treatability Test for the Hanford Central Plateau: Interim Post-Desiccation Monitoring Results
}

\author{
MJ Truex \\ M Oostrom \\ CE Strickland \\ TC Johnson \\ CD Johnson \\ RE Clayton \\ GB Chronister ${ }^{1}$
}

September 2013

Prepared for

the U.S. Department of Energy

under Contract DE-AC05-76RL01830

Pacific Northwest National Laboratory

Richland, Washington 99352

\footnotetext{
${ }^{1}$ CH2M HILL Plateau Remediation Company, Richland, Washington.
} 


\section{Summary}

Over decades of operation, the U.S. Department of Energy (DOE) and its predecessors have released nearly 2 trillion L ( 450 billion gal) of liquid into the vadose zone at the Hanford Site. Much of this liquid waste discharge into the vadose zone occurred in the Central Plateau, a $200 \mathrm{~km}^{2}\left(75 \mathrm{mi}^{2}\right)$ area that includes approximately 800 waste sites. Some of the inorganic and radionuclide contaminants in the deep vadose zone at the Hanford Site are at depths below the limit of direct exposure pathways, but may need to be remediated to protect groundwater. The Tri-Party Agencies (DOE, U.S. Environmental Protection Agency, and Washington State Department of Ecology) established Milestone M-015-50, which directed DOE to submit a treatability test plan for remediation of technetium-99 (Tc-99) and uranium in the deep vadose zone. These contaminants are mobile in the subsurface environment and have been detected at high concentrations deep in the vadose zone, and at some locations have reached groundwater. Testing technologies for remediating Tc-99 and uranium will also provide information relevant for remediating other contaminants in the vadose zone. A field test of desiccation is being conducted as an element of the DOE test plan published in March 2008 to meet Milestone M-015-50. Desiccation technology relies on removal of water from a portion of the subsurface such that the resultant low moisture conditions inhibit downward movement of water and dissolved contaminants. Previously, a field test report was prepared describing the active desiccation portion of the test and initial post-desiccation monitoring data and submitted in response to Milestone M-015-110D. Additional monitoring data have been collected at the field test site during the post-desiccation period and are reported herein along with interpretation with respect to desiccation performance. This is an interim report including about 2 years of post-desiccation monitoring data. The DOE field test plan includes a total of 5 years of post-desiccation monitoring.

The desiccation field test was conducted at the Hanford Site 200-BC-1 Operable Unit. This waste site contains 26 cribs and trenches that received about 110 million L (29 million gal) of liquid waste primarily in the mid-1950s. The waste contained about 410 curies of Tc-99. There is no evidence the

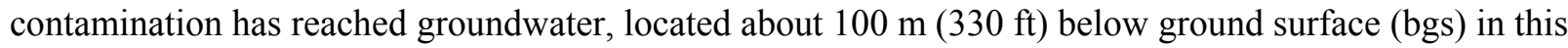
area. Initial characterization efforts indicated the Tc-99 inventory is located mostly at a depth in the vadose zone of between about 30 and $70 \mathrm{~m} \mathrm{(98} \mathrm{and} 230 \mathrm{ft}$ ) bgs. However, transport model predictions have indicated the potential for this contamination to adversely affect groundwater in the future.

The treatability test is being conducted to provide information about desiccation that can be used in subsequent feasibility studies for waste sites with inorganic and radionuclide contaminants in the deep vadose zone. Test site characterization was conducted as described in a characterization work plan. Results of the characterization effort have been previously reported by DOE and others. The DOE field test plan was prepared and used to guide the desiccation field testing effort. The active desiccation portion of the field test occurred over a duration of 164 days, ending on June 30, 2011. The injection and extraction wells were $12 \mathrm{~m}$ apart with multiple monitored locations surrounding the injection well. A clustered monitoring approach was used in the test whereby a borehole (sensor borehole) containing sensors, gas-sampling ports, and electrical resistance tomography electrodes was placed nominally adjacent to a cased, unscreened well (logging well) that was used to conduct neutron moisture logging and for application of cross-hole ground penetrating radar (GPR). Monitoring with the in situ sensors and geophysical techniques has been continued for the post-desiccation (rewetting) phase of the test.

Over time, the rate of moisture rewetting of the desiccated zones is a function of the hydraulic gradient, water relative permeability, and porous media unsaturated flow properties. Rewetting data since 
the end of active desiccation are consistent with expectations based on related laboratory data and numerical simulation analyses. Analysis of the data demonstrate that water advection from relatively wetter zones to dryer zones has occurred. For the zone of most extensive desiccation, nominally between 14 and $16 \mathrm{~m}$ bgs, water advection has occurred primarily vertically downward from the moister lowerpermeability sediments shallower than $14 \mathrm{~m}$ bgs that were not significantly dried during desiccation operations. At many locations, a substantial portion of the water removed by desiccation has returned to the desiccation zone over the 2-year rewetting monitoring period. This relatively rapid rewetting was expected based on the moisture conditions within and adjacent to these locations. Rewetting rate data show an initial period of a relatively linear rewetting rate followed by a slowing of the rate as the moisture content nears local hydraulic equilibrium conditions. In the monitored zones showing the thickest vertical intervals of desiccation, rewetting increased moisture content in the shallow portion of the desiccated zone, but other portions remain dry. Continued monitoring will be useful to evaluate the rate of rewetting for these thicker desiccation zones. To date, rewetting data are consistent with expectations for desiccation test performance based on laboratory and numerical simulations. These data are important to provide confidence in the design process to scale-up desiccation from the small test-site scale to a larger scale with sufficient capacity to maintain dry conditions over long periods of time and help mitigate contaminant flux to groundwater. 


\section{Acronyms and Abbreviations}

$\begin{array}{ll}2 \mathrm{D} & \text { two-dimensional } \\ 3 \mathrm{D} & \text { three-dimensional } \\ \mathrm{bgs} & \text { below ground surface } \\ \mathrm{cfm} & \text { cubic feet per minute } \\ \mathrm{cm} & \text { centimeter(s) } \\ \mathrm{C}_{\mathrm{R}} & \text { count ratio } \\ \mathrm{DOE} & \text { U.S. Department of Energy } \\ \mathrm{EC} & \text { electrical conductivity } \\ \mathrm{EPA} & \text { U.S. Environmental Protection Agency } \\ \mathrm{ERT} & \text { electrical resistivity tomography } \\ \mathrm{GPR} & \text { ground penetrating radar } \\ \mathrm{HDU} & \text { Heat Dissipation Unit } \\ \mathrm{kPa} & \text { kilopascal(s) } \\ \mathrm{L} & \text { liter(s) } \\ \mathrm{m} & \text { meter(s) } \\ \mathrm{m}^{3} & \text { cubic meter(s) } \\ \mathrm{mA} & \text { milliampere(s) } \\ \mathrm{mbar} & \text { millibar(s) } \\ \mathrm{MHz} & \text { megahertz } \\ \mathrm{min} & \text { minute(s) } \\ \mathrm{MPa} & \text { megapascal(s) } \\ \mathrm{PNNL} & \text { Pacific Northwest National Laboratory } \\ \mathrm{s} & \text { second(s) } \\ \mathrm{S} / \mathrm{m} & \text { siemen(s)/m } \\ \mathrm{TCP} & \text { Thermocouple Psychrometer } \\ \mathrm{VMC} & \text { volumetric moisture content } \\ \mathrm{VMC} & \text { volumetric moisture content at the end of active desiccation } \\ & \end{array}$




\section{Contents}

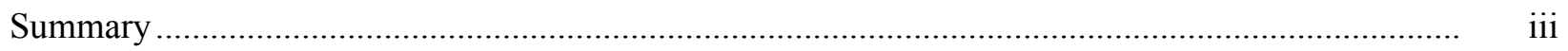

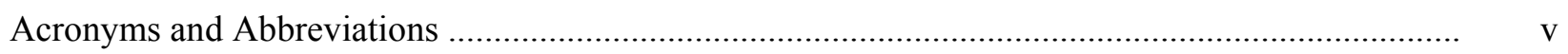

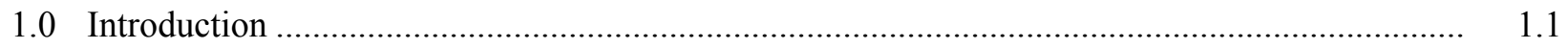

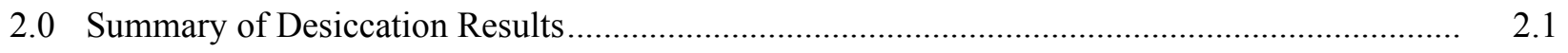

3.0 Post-Desiccation Monitoring Approach ....................................................................... 3.1

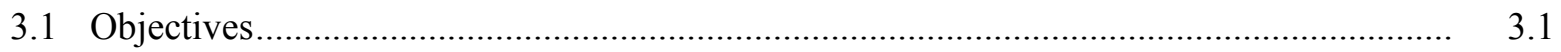

3.2 Experimental Design and Procedures.......................................................................... 3.1

3.2.1 Test Site Background ......................................................................... 3.1

3.2.2 Test Layout, Operations, and Equipment ........................................................ 3.4

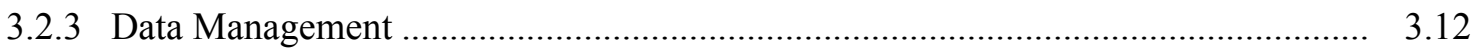

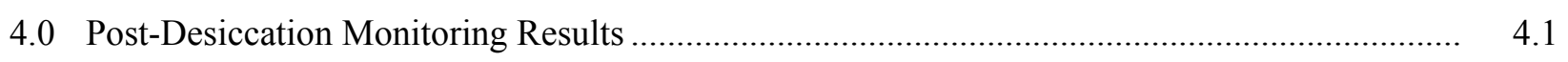

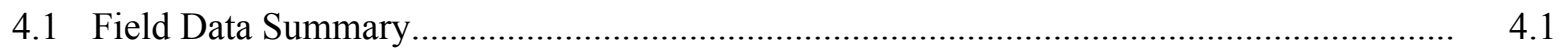

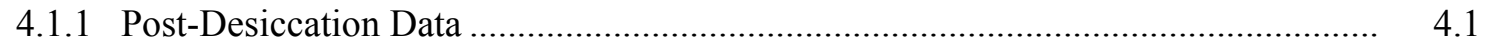

4.2 Post-Desiccation Monitoring Data Assessment .............................................................. 4.17

4.2.1 Previous Assessment of Rewetting .................................................................. 4.17

4.2.2 Assessment of Field Test Rewetting Data......................................................... 4.18

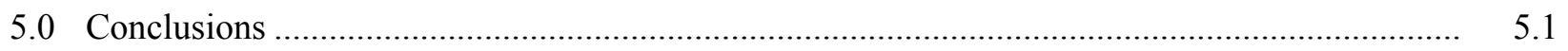

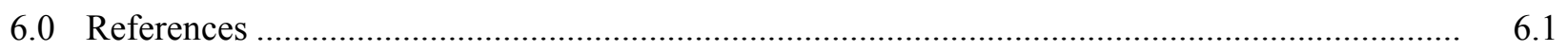




\section{Figures}

3.1 Test Site Location in the BC Cribs and Trenches Area of the Hanford Site............................ 3.2

3.2 Injection Well Borehole Data and Screened Interval.......................................................... 3.3

3.3 Injection and Extraction Well Borehole Initial Laboratory Moisture Content, Extracted Pore Water Electrical Conductivity, and Well Screened Interval ............................................ 3.4

3.4 Basic Components of the Desiccation Field Test System ..................................................... 3.5

3.5 Flow Conditions and Cumulative Volumes for Field Test Operations ................................... 3.6

3.6 Location of Test Site Logging Wells, Sensor Boreholes, and Post-Desiccation Boreholes for Collection of Sediment Samples.....

3.7 Calibration Relation for Neutron Moisture Probe Count Ratio Data and Corresponding Laboratory-Measured Volumetric Moisture Content.

4.1 Post-Desiccation Temperature Response over Time for the Sensors at a Depth of $32.5 \mathrm{ft}$ bgs.

4.2 Post-Desiccation Temperature Response over Time for the Sensors at a Depth of $36.5 \mathrm{ft}$ bgs.

4.3 Post-Desiccation Temperature Response over Time for the Sensors at a Depth of $42.5 \mathrm{ft}$ bgs.

4.4 Post-Desiccation Temperature Response over Time for the Sensors at a Depth of $46.5 \mathrm{ft}$ bgs.

4.5 Post-Desiccation Heat Dissipation Unit Response over Time for the Sensors at a Depth of $42.5 \mathrm{ft}$ bgs.

4.6 Post-Desiccation Heat Dissipation Unit Response over Time for the Sensors at a Depth of $47.5 \mathrm{ft}$ bgs.

4.7 Post-Desiccation Relative Humidity Probe Response over Time for the Sensors at a Depth of $42.5 \mathrm{ft}$ bgs.

4.8 Post-Desiccation Relative Humidity Probe Response over Time for the Sensors at a Depth of $47.5 \mathrm{ft}$ bgs.

4.9 Neutron Moisture Probe Response over Time for Location C7523.

4.10 Neutron Moisture Probe Response over Time for Location C7525 ...................................... 4.8

4.11 Neutron Moisture Probe Response over Time for Location C7527 ....................................... 4.9

4.12 Neutron Moisture Probe Response over Time for Location C7529 ....................................... 4.10

4.13 Neutron Moisture Probe Response over Time for Location C7531 ....................................... 4.11

4.14 Neutron Moisture Probe Response over Time for Location C7533 ........................................ 4.12

4.15 Neutron Moisture Probe Response over Time for Location C7537 ........................................ 4.13

4.16 2D Interpretation of Volumetric Moisture Content from Cross-Hole Ground Penetrating Radar Data during Desiccation at Day 137 and after the End of Active Desiccation at Days 193 and 265.

4.17 2D Interpretation of Initial Volumetric Moisture Content from Cross-Hole Ground Penetrating Radar Data Prior to Desiccation...

4.18 2D image showing regions where GPR low-loss conditions are valid resulting in higher confidence in GPR-derived moisture content estimates. 
4.19 Ratio of Volumetric Moisture Content to the Volumetric Moisture Content at the End of Active Desiccation Over Time along the Axis between the Injection and Extraction Wells from Cross-Hole Electrical Resistivity Tomography. ERT data are from sensors at locations C7522-C7534 through day 270 of the post-desiccation period.

4.20 Ratio of Volumetric Moisture Content to the Volumetric Moisture Content at the End of Active Desiccation Over Time along the Axis between the Injection and Extraction Wells from Cross-Hole Electrical Resistivity Tomography. ERT data are from sensors at locations C7522-C7534 for days 650 and 770 of the post-desiccation period.

4.21 Horizontal Rewetting of the 44-55-ft bgs Desiccated Zone Excluding Water Supply from above $44 \mathrm{ft}$ bgs at 0,770 Days, and 10 Years after Desiccation Ceased.

4.22 Rewetting Volume $\left(\mathrm{L} / \mathrm{m}^{2}\right)$ Estimates as a Function of Rewetting Time

4.23 Simulated Rewetting at Location C7527 as a Function of Time as a Result of Water Injection over 770 Days at $44 \mathrm{ft}$ bgs with an Average Rate Computed from Figure 4.22

\section{Tables}

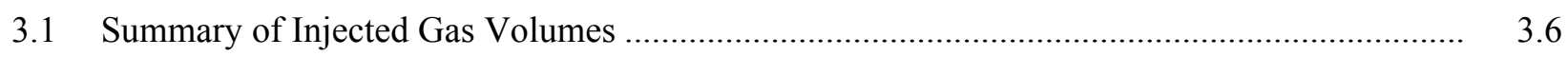

3.2 Field Site Monitoring Locations …................................................................................. 3.8 


\subsection{Introduction}

Some of the inorganic and radionuclide contaminants in the vadose zone at the Hanford Site are at depths below the limit of direct exposure pathways, but may need to be remediated to protect groundwater (DOE/RL 2008a). However, remediation options for contamination deep in the vadose zone are limited by the physical and hydrogeologic properties of the vadose zone (Dresel et al. 2011). In response to the Tri-Party Agreement Milestone M-015-50, the Deep Vadose Treatability Test Plan for the Hanford Central Plateau was issued in March 2008 (DOE/RL 2008a). This plan is for a treatability test program to evaluate potential deep vadose zone remedies for groundwater protection. The field test of vadose zone desiccation was conducted (Truex et al. 2012a) and continued post-desiccation monitoring is now under way as part of this effort.

The Hanford Site 200-BC-1 Operable Unit (the BC Cribs and Trenches Area) has subsurface conditions that serve as an example of vadose zone contamination issues and was selected as the location of the desiccation field test site. This waste site contains 26 cribs and trenches that received about 110 million liters of liquid waste primarily in the mid-1950s. The waste contained about 410 curies of technetium-99 (Tc-99) (Corbin et al. 2005). There is no evidence the contamination has reached groundwater, located about $100 \mathrm{~m}$ below ground surface (bgs) in this area. Initial characterization efforts indicated the Tc-99 inventory is located mostly at a depth in the vadose zone of between about 30 and $70 \mathrm{~m}$ bgs. However, transport model predictions indicated the potential for this contamination to adversely affect groundwater in the future (Ward et al. 2004). The groundwater contaminant concentrations that can result from vadose zone contamination are a function of the rate of contaminant movement through the vadose zone. For remediation, the magnitude of contaminant discharge from the vadose zone to the groundwater must be maintained low enough to achieve groundwater protection goals.

Desiccation of a portion of the vadose zone, in conjunction with a surface infiltration barrier, has the potential to minimize migration of deep vadose zone contaminants towards the water table (Truex et al. 2011). To apply desiccation, a dry gas is injected into the subsurface. The dry gas evaporates water from the porous medium until the gas reaches $100 \%$ relative humidity after which the gas can no longer evaporate water. Evaporation can remove pore water and may result in very low moisture contents and decreased water relative permeability in the desiccated zone (Ward et al. 2008; Oostrom et al. 2009, 2012a and b; Truex et al. 2011, 2012a and b, 2013). Because of these desiccation-induced changes, the future rate of movement of moisture and contaminants through this zone is decreased.

Laboratory and modeling studies have been conducted to study desiccation and provide a technical basis for its use as a potential remedy (Truex et al. 2011; Ward et al. 2008; Oostrom et al. 2009, 2011, $2012 \mathrm{a}$ and $\mathrm{b}$ ). In these studies, the overall performance of desiccation in limiting water and contaminant flux to the groundwater was shown to be a function of the final moisture content, contaminant concentration, sediment properties, size of the desiccated zone, the hydraulic properties and conditions in surrounding subsurface zones, and the net surface recharge rate. In the laboratory, desiccation was shown to be capable of reducing the moisture content to below the residual moisture content of the porous medium (Truex et al. 2011; Ward et al. 2008; Oostrom et al. 2009). Data from the field test of desiccation also demonstrated reduction of moisture content to below the residual moisture content of the porous medium in some locations near the dry-gas injection well (Truex et al. 2012a and b, 2013). However, the desiccation during the field test varied as a function of subsurface properties, flow patterns of the dry gas, and time, producing a range of moisture content reductions throughout the monitored portion of the test site. 


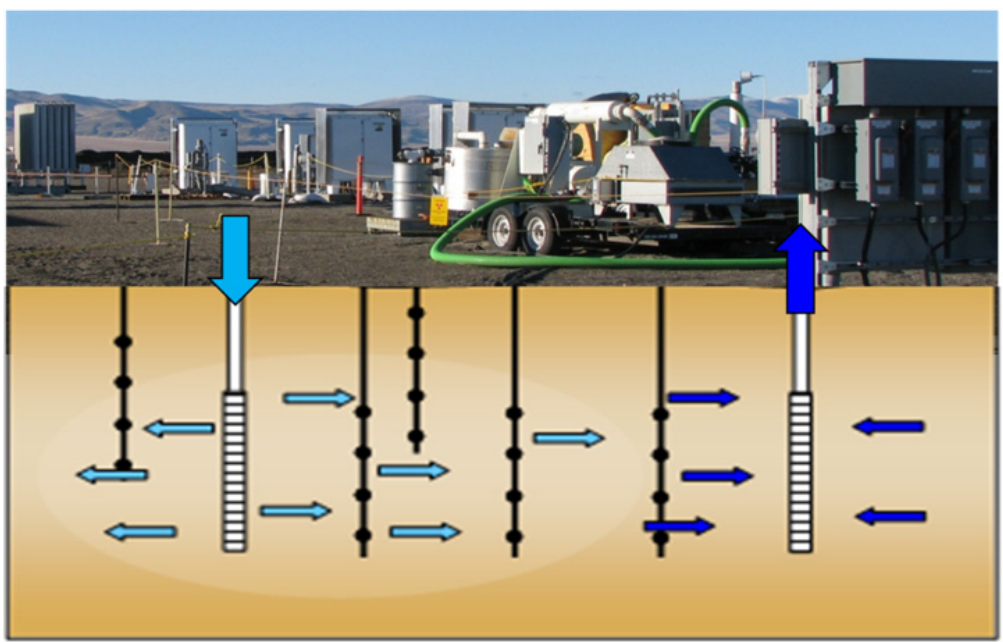

Soil Desiccation Test Site and Depiction of Subsurface Gas Flow
After a portion of the vadose zone is desiccated, rewetting of this zone can occur by vapor- and aqueous-phase moisture transport. The timescale of rewetting is related to the overall performance of desiccation in minimizing contaminant flux to the groundwater. Truex et al. (2011) examined rewetting of desiccated zones in the laboratory and found that vapor-phase rewetting from adjacent humid soil gas, in the absence of advective soil gas movement, occurs slowly by diffusion of water vapor and increases the moisture content of

desiccated porous medium to a limited extent, nominally to near the residual moisture content for the porous medium. The aqueous-phase rewetting rate was found to be a function of the relative aqueousphase permeability of the porous medium and hydraulic capillary pressure gradients.

This report describes and interprets post-desiccation monitoring conducted at the field test site, extending the information about rewetting processes and rates presented in the initial field treatability test report and associated journal articles (Truex et al. 2012a and b, 2013). This is an interim report including about 2 years of post-desiccation monitoring data. The field test plan (DOE/RL 2010b) includes a total of 5 years of post-desiccation monitoring. Section 2.0 provides a summary of the results of active desiccation. The monitoring approach is described in Section 3.0, followed by a presentation of the postdesiccation monitoring results in Section 4.0. Section 5.0 presents conclusions from the post-desiccation data collected to date. 


\subsection{Summary of Desiccation Results}

The objectives outlined in the field test plan (DOE/RL 2010b) associated with active desiccation were successfully addressed through the field testing and associated laboratory and modeling efforts conducted as part of the treatability test. In the field test, a portion of the subsurface was desiccated, creating conditions that reduce the rate of moisture and contaminant movement toward the groundwater. A design basis to apply desiccation for vadose zone remediation was developed and is available for use in subsequent feasibility and remedial design efforts (Truex et al. 2012a).

The distribution, rate, and extent of desiccation observed in the field were affected by subsurface heterogeneity; however, over time the moisture content in initially wetter, lower-permeability zones of limited extent was also reduced. Field test results were consistent with expectations based on previous laboratory and modeling efforts that investigated aspects of the desiccation process. Note the field test targeted applying desiccation in a portion of the subsurface with significant contrasts in permeability to enable evaluation of the performance of desiccation across multiple types of subsurface conditions. Fullscale application of desiccation would seek target depth intervals for dry gas injection that enable creation of thick desiccated zones and would avoid zones where injected gas flow would be minimal.

The test results and related laboratory and modeling efforts provide information to guide design and implementation of desiccation. Desiccation observed in the field test was consistent with design calculations and simulations based on the water-holding capacity of the injected gas. In addition, the distribution of desiccated zones met expectations; higher permeability zones dried first, followed by expansion of desiccation into lower-permeability zones over time. Analysis of data and use of numerical simulations indicate that full-scale designs can be made more cost effective than the design of the field test (which was designed to collect specific data, not as a full-scale remediation) by using ambient air as the injected dry gas and by using an injection-only design (i.e., no extraction well).

Selected results from pre-desiccation characterization and active desiccation are incorporated into this report to provide a starting point and context for interpreting post-desiccation data. Detailed description of pre-desiccation data and the active desiccation test results are available in the following reports and articles.

$\underline{\text { Reports }}$

- Truex MJ, M Oostrom, CE Strickland, TC Johnson, VL Freedman, CD Johnson, WJ Greenwood, AL Ward, RE Clayton, MJ Lindberg, JE Peterson, SS Hubbard, GB Chronister, and MW Benecke. 2012. Deep Vadose Zone Treatability Test for the Hanford Central Plateau: Soil Desiccation Pilot Test Results. PNNL-21369, Pacific Northwest National Laboratory, Richland, Washington.

- Truex MJ, M Oostrom, VL Freedman, C Strickland, and AL Ward. 2011. Laboratory and Modeling Evaluations in Support of Field Testing for Desiccation at the Hanford Site. PNNL-20146, Pacific Northwest National Laboratory, Richland, Washington.

- Um W, RJ Serne, MJ Truex, AL Ward, MM Valenta, CF Brown, C Iovin, KN Geiszler, IV Kutnyakov, ET Clayton, H-S Chang, SR Baum, and DM Smith. 2009. Characterization of Sediments from the Soil Desiccation Pilot Test (SDPT) Site in the BC Cribs and Trenches Area. PNNL-18800, Pacific Northwest National Laboratory, Richland, Washington. 
- DOE/RL (U.S. Department of Energy, Richland Operations Office). 2010a. Characterization of the Soil Desiccation Pilot Test Site. DOE/RL-2009-119, Rev. 0, Richland, Washington.

- Ward AL, M Oostrom, and DH Bacon. 2008. Experimental and Numerical Investigations of Soil Desiccation for Vadose Zone Remediation: Report for Fiscal Year 2007. PNNL-17274, Pacific Northwest National Laboratory, Richland, Washington.

$\underline{\text { Articles }}$

- Truex MJ, TC Johnson, CE Strickland, JE Peterson, and SS Hubbard. 2013. "Monitoring Vadose Zone Desiccation with Geophysical Methods.” Vadose Zone Journal doi:10.2136/vzj2012.0147

- Oostrom M, VL Freedman, TW Wietsma, and MJ Truex. 2012. "Effects of porous medium heterogeneity on vadose zone desiccation: Intermediate-scale laboratory experiments and simulations." Vadose Zone Journal doi:10.2136/vzj2011.0168.

- Truex MJ, M Oostrom, CE Strickland, GB Chronister, MW Benecke, and CD Johnson. 2012. "Field-Scale Assessment of Desiccation Implementation for Deep Vadose Zone Contaminants." Vadose Zone Journal doi:10.2136/vzj2011.0144

- Chronister GB, MJ Truex, and MW Benecke. 2012. "Soil Desiccation Techniques - Strategies for Immobilization of Deep Vadose Contaminants at the Hanford Central Plateau." In Proceedings of Waste Management Symposia 2012.

- Truex MJ, M Oostrom, JE Szecsody, CE Strickland, GB Chronister, and MW Benecke. 2012. "Technical Basis for Gas-Phase Vadose Zone Remediation Technologies at Hanford: A Review." In Proceedings of Waste Management Symposia 2012.

- Oostrom M, TW Wietsma, CE Strickland, VL Freedman, and MJ Truex. 2012. "Instrument Testing during Desiccation and Rewetting at the Intermediate Laboratory Scale. Vadose Zone Journal doi:10.2136/vzj2011.0089.

- Oostrom M, GD Tartakovsky, TW Wietsma, MJ Truex, and JH Dane. 2011. "Determination of Water Saturation in Relatively Dry and Desiccated Porous Media Using Gas-Phase Partitioning Tracer Tests. Vadose Zone Journal 10:1-8; doi:10.2136/vzj2010.0101.

- Oostrom M, TW Wietsma, JH Dane, MJ Truex, and AL Ward. 2009. "Desiccation of Unsaturated Porous Media: Intermediate-Scale Experiments and Numerical Simulation." Vadose Zone Journal 8:643-650. 


\subsection{Post-Desiccation Monitoring Approach}

The post-desiccation monitoring approach featured an experimental design and procedures developed to meet the test objectives presented in the field test plan (DOE 2010b).

\subsection{Objectives}

The objectives relevant to the post-desiccation monitoring phase of the test are as follows:

- Desiccation Field Test Performance: Demonstrate field-scale desiccation for targeted areas within the vadose zone.

- After desiccation is completed, determine the rate of change in soil moisture for the desiccated zone.

- Determine the best types of instrumentation for monitoring key subsurface and operational parameters to provide feedback to operations and evaluate long-term effectiveness.

\subsection{Experimental Design and Procedures}

The experimental design and procedures are described by Truex et al. (2012a) and briefly summarized below to provide context for the post-desiccation monitoring effort.

\subsubsection{Test Site Background}

The field treatability test for desiccation was conducted in the Hanford Site 200-BC-1 Operable Unit, commonly referred to as the BC Cribs and Trenches Area (Figure 3.1). The site was selected for the field test because relatively high concentrations of mobile Tc-99 contamination and high moisture contents are present at relatively shallow depths, facilitating test operations, yet representing conditions found deeper in the vadose zone where desiccation could be considered as part of a remedy. For the test, the deep vadose zone was mimicked by covering the ground surface with an impermeable barrier to limit surface interaction with the test injection and extraction operations. The test area is located between adjacent waste disposal cribs where the subsurface was affected by lateral movement of crib discharges in the subsurface but drilling and other test operations could take place outside the hazardous footprint of the former disposal cribs. Figure 3.2 shows the vertical stratigraphy, technetium, and moisture distribution at the injection well location in relation to the well screen interval. Porous media grain-size variations in the test interval generally range from sands to loamy sands with some zones of silty sand and silt, similar to the porous media observed throughout the full-depth interval. 


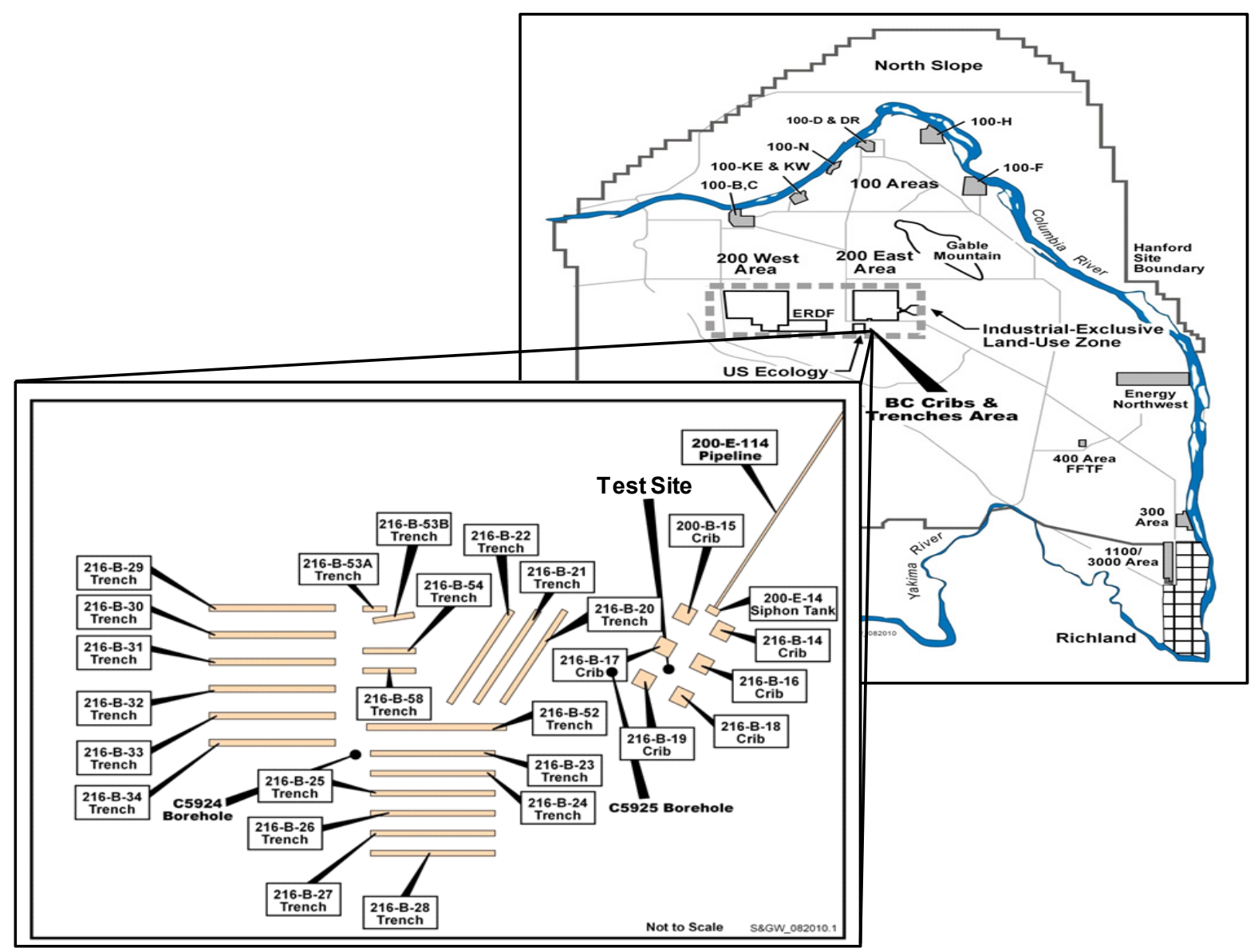

Figure 3.1. Test Site Location in the BC Cribs and Trenches Area (inset, 200-BC-1 Operable Unit) of the Hanford Site (map) (after DOE 2010b). Note the test site is centered around borehole C7523, one of three characterization boreholes (C7523, C7524, C7525) from site investigation activities associated with electrical resistivity studies at the site (Serne et al. 2009). 


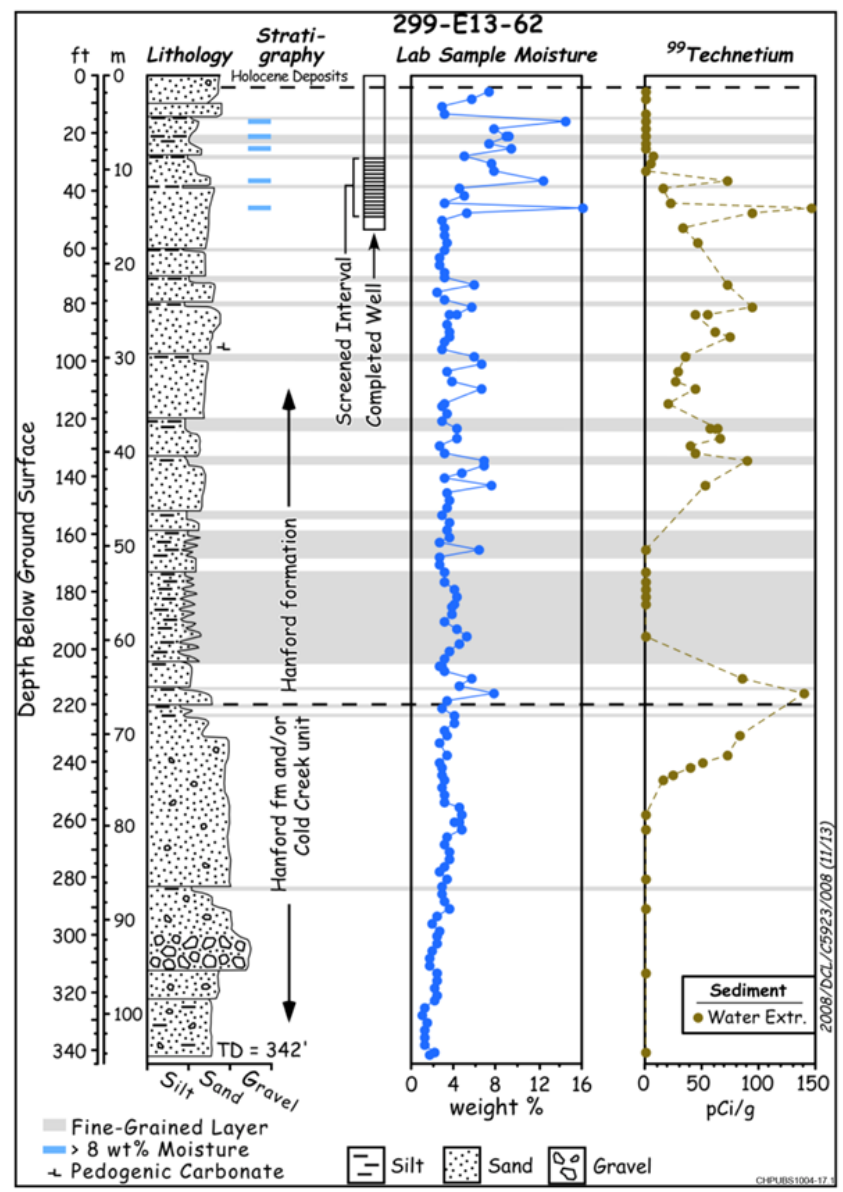

Figure 3.2. Injection Well Borehole Data and Screened Interval (after DOE 2010b)

Borehole neutron logs and laboratory analysis of samples were conducted to evaluate the vertical distribution of moisture and contaminant concentrations at the injection and extraction well locations of the field test site (Figure 3.3) (Serne et al. 2009; Um et al. 2009). 


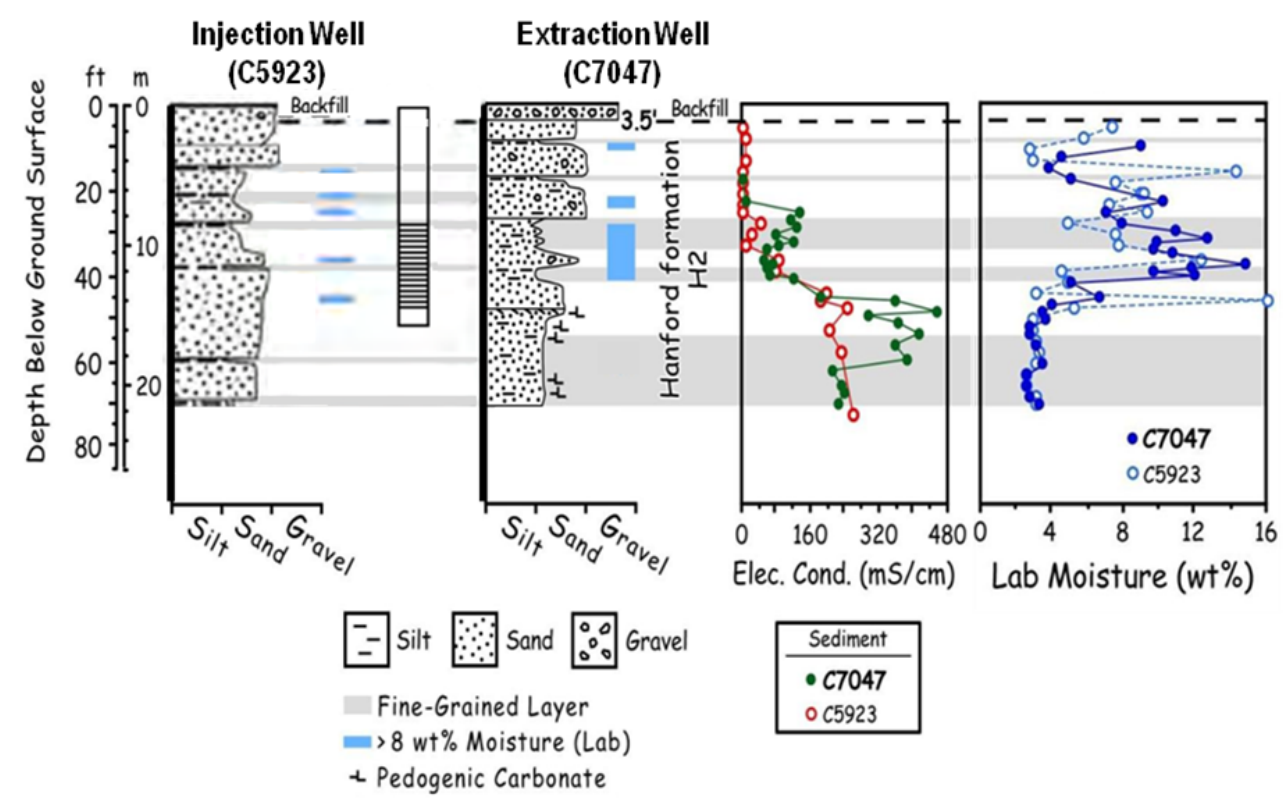

Figure 3.3. Injection and Extraction Well Borehole Initial Laboratory Moisture Content, Extracted Pore Water Electrical Conductivity, and Well Screened Interval (after DOE 2010a; Serne et al. 2008; Um et al. 2009)

\subsubsection{Test Layout, Operations, and Equipment}

The desiccation technology relies on removal of water from a portion of the subsurface such that the resultant low moisture conditions inhibit downward movement of water and dissolved contaminants. Implementation requires establishing sufficiently dry conditions within the targeted zone to effectively inhibit downward water transport. Nominally, the targeted zone would need to extend laterally across the portion of the vadose zone where contaminants have the potential to move downward at a flux that will affect groundwater above the remediation objective groundwater concentration. Thus, the experimental design was developed to evaluate the process of establishing a desiccated zone that extends laterally away from a dry gas injection well within a specific depth interval of the vadose zone. To obtain this type of desiccation zone, the field test design used a dipole configuration with injection of nitrogen and extraction of soil gas through wells screened in a target depth interval to favor soil gas flow within this interval and within a defined monitoring zone (Figure 3.4). 


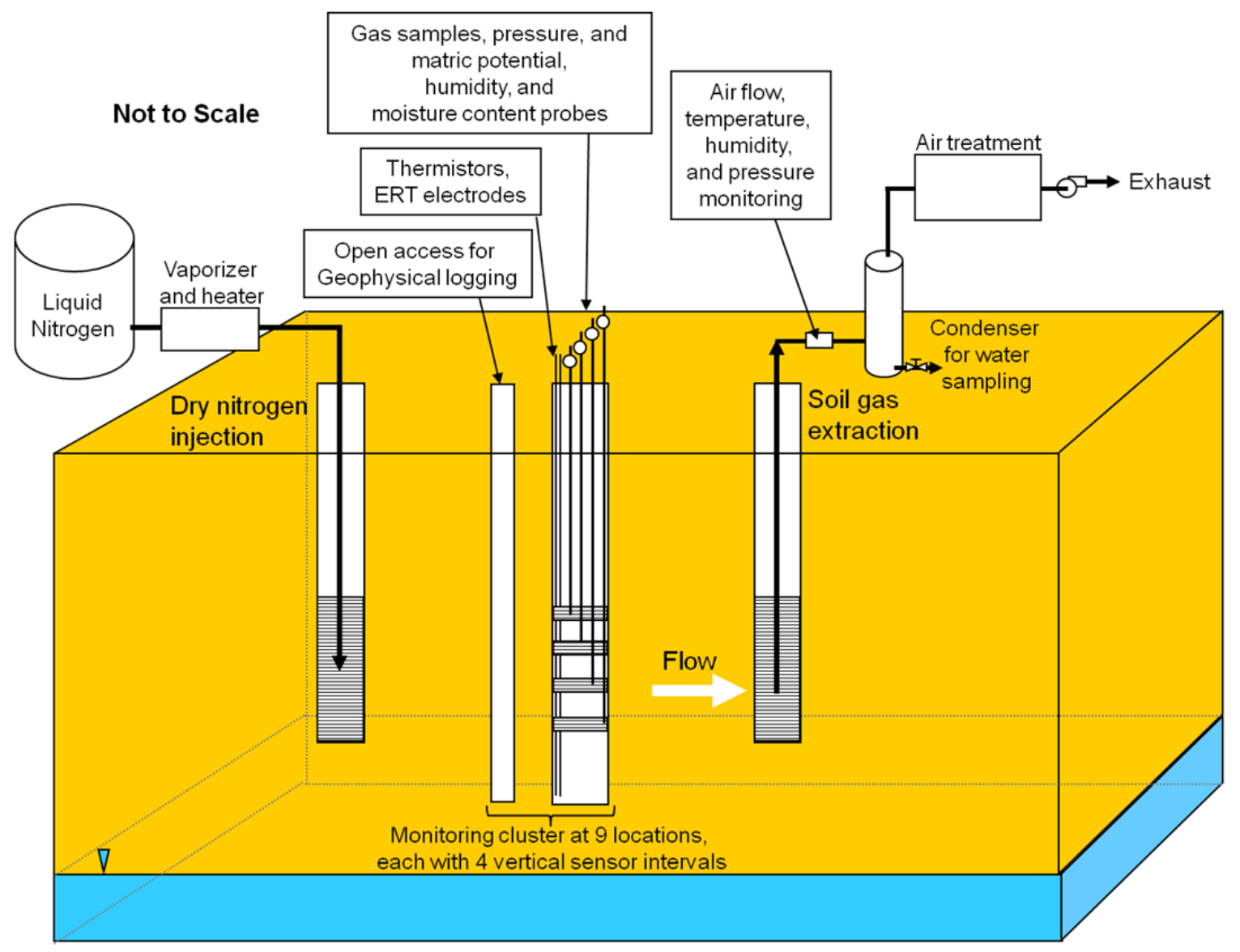

Figure 3.4. Basic Components of the Desiccation Field Test System

The general operational and in situ monitoring strategy is depicted in Figure 3.4. Dry nitrogen gas produced from liquid nitrogen tankers was injected at a controlled temperature of $20^{\circ} \mathrm{C}$ into a screened interval from 9.1 to $15.2 \mathrm{~m} \mathrm{(30} \mathrm{to} 50 \mathrm{ft}$ ) bgs. Equipment testing, including trial nitrogen gas injections and the initial tracer test, occurred between November 22 and December 6, 2010. The active desiccation portion of the field test occurred with nitrogen injection at a stable flow rate of $510 \mathrm{~m}^{3} / \mathrm{h}(300$ cubic feet per minute [cfm]) from January 17, 2011, through June 30, 2011, (164 days) except during a 13-day interval from April 21 through May 4, 2011, when there was no injection. Extraction of soil gas from a well screened from 9.1 to $15.2 \mathrm{~m} \mathrm{(30}$ to $50 \mathrm{ft}$ ) bgs was maintained for the full test duration at a stable flow rate of $170 \mathrm{~m}^{3} / \mathrm{h}(100 \mathrm{cfm})$. Extracted soil gas was routed through a heat exchanger to condense water that was collected and periodically sampled. The injection and extraction wells were $12 \mathrm{~m}$ apart.

Operational data were collected during injection and extraction operations at the test site. Of these parameters, the injected gas flow rate and temperature are key drivers for desiccation. Dry nitrogen (relative humidity of zero) was used for the injection gas during the test (Table 3.1). Extraction parameters were also measured to define test conditions, but are not specifically related to the desiccation rate other than the impact on soil gas flow rates and patterns. Figure 3.5 shows the operational parameter data of injection gas flow and extraction flow rate for the duration of active desiccation. Injection gas temperature was held essentially constant at about $20^{\circ} \mathrm{C}$. 
Table 3.1. Summary of Injected Gas Volumes

\begin{tabular}{llllc}
\hline \multicolumn{2}{c}{ Time On } & \multicolumn{2}{c}{ Time Off } & Cumulative Volume Injection $\left(\mathrm{m}^{3}\right)$ \\
\hline $11 / 22 / 2010$ & $09: 00$ & $11 / 23 / 2010$ & $10: 24$ & 12,812 \\
$11 / 29 / 2010$ & $11: 13$ & $11 / 30 / 2010$ & $08: 20$ & 16,354 \\
$12 / 2 / 2010$ & $09: 40$ & $12 / 6 / 2010$ & $11: 40$ & 32,969 \\
$1 / 17 / 2011$ & $15: 35$ & $4 / 21 / 2011$ & $13: 00$ & $1,108,884$ \\
$5 / 2 / 2011$ & $12: 30$ & $5 / 2 / 2011$ & $12: 45$ & $1,109,014$ \\
$5 / 4 / 2011$ & $10: 15$ & $6 / 30 / 2011$ & $13: 55$ & $1,799,790$ \\
\hline
\end{tabular}

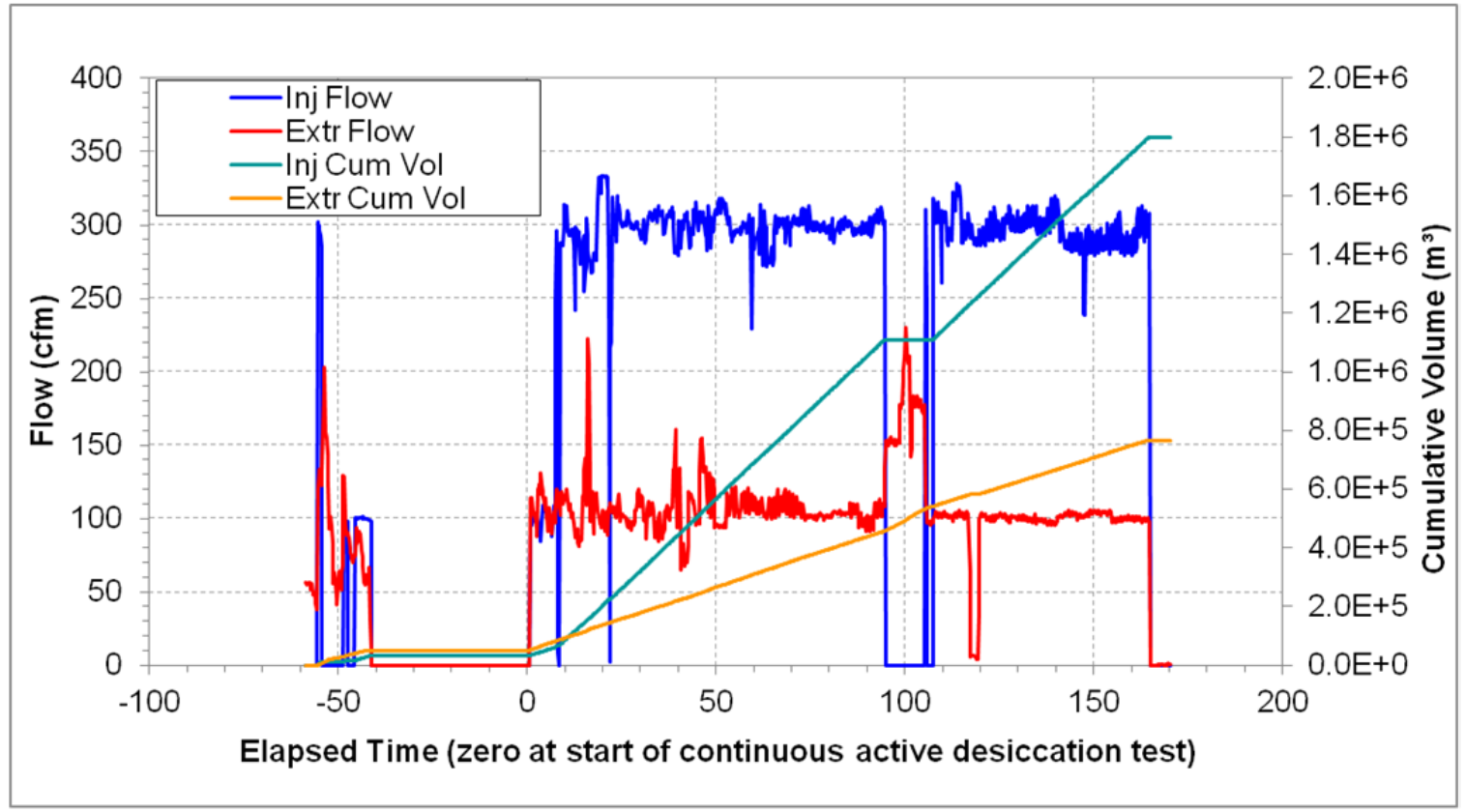

Figure 3.5. Flow Conditions and Cumulative Volumes for Field Test Operations

Figure 3.6 depicts the lateral layout of injection and extraction wells and the monitoring locations. Distances from the injection well to the monitoring locations are listed in Table 3.2. A 30-m by 45-m gas-impermeable membrane barrier was installed at the surface centered over the well network. A clustered monitoring approach was used in the test whereby a borehole (sensor borehole) containing sensors, gas-sampling ports, and electrical resistance tomography electrodes was placed nominally adjacent to a cased, unscreened well (logging well) that was used to conduct neutron moisture logging and for application of cross-hole ground penetrating radar (GPR). Sensor boreholes contained four intervals of 100-mesh $(>0.125$ and $<0.149 \mathrm{~mm}$ ) Colorado sand (Colorado Silica, Colorado Springs, Colorado) containing matric potential sensors, moisture content sensors, humidity sensors (sensors described in Section 3.2.2.1), and porous polyethylene gas-sampling ports (model X-6081, Porex Technologies Corporation) separated by granular bentonite. The sand intervals were placed nominally at

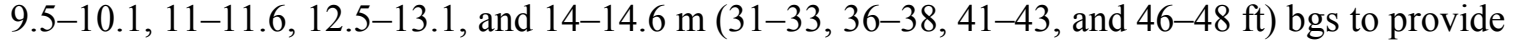
vertically discrete monitoring across the injection/extraction well screen interval. The boreholes

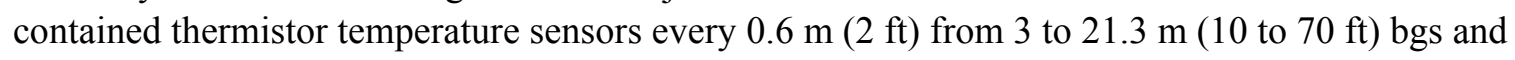
electrical resistivity electrodes every $1.5 \mathrm{~m}(5 \mathrm{ft})$ within the bentonite intervals of the borehole fill 
material from 3 to $21.3 \mathrm{~m}$ (10 to $70 \mathrm{ft}$ ) bgs. Electrical resistivity tomography (ERT) electrodes were placed within the bentonite zones with tubing was installed to enable the addition of water around each electrode to locally hydrate the bentonite and maintain effective coupling between the electrode and the subsurface. Electrical connectivity was checked periodically during the test and water added when necessary to maintain adequate coupling. Logging wells to provide access for neutron moisture logging and cross-hole GPR extended to $21.3 \mathrm{~m} \mathrm{(70} \mathrm{ft)} \mathrm{bgs} \mathrm{with} \mathrm{a} \mathrm{2-in.} \mathrm{polyvinyl} \mathrm{chloride} \mathrm{casing} \mathrm{(plugged} \mathrm{at} \mathrm{the}$ bottom) in a 4-in.-diameter borehole and 100-mesh Colorado sand in the annular space.

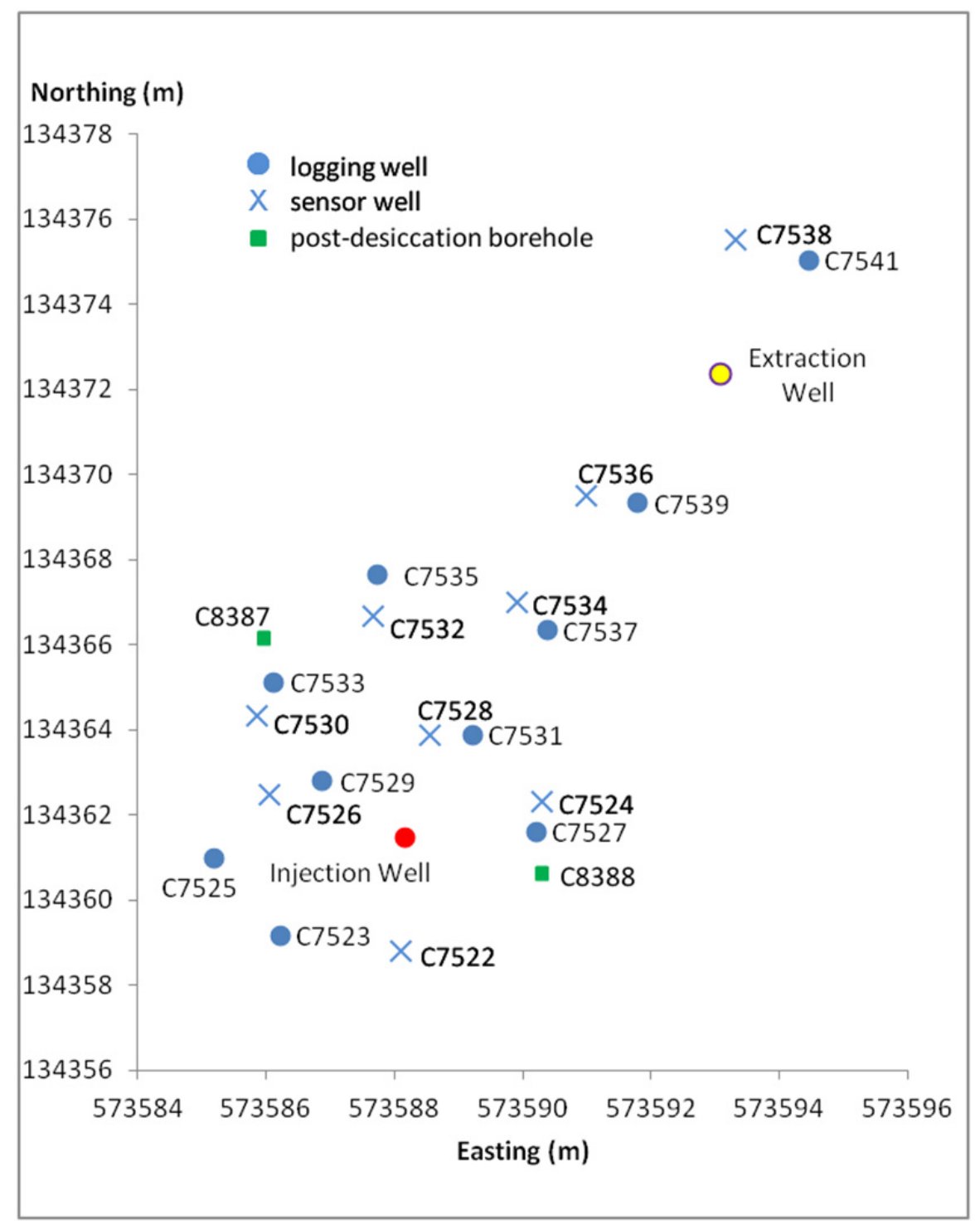

Figure 3.6. Location of Test Site Logging Wells, Sensor Boreholes, and Post-Desiccation Boreholes for Collection of Sediment Samples. A background sensor borehole (C7540, not shown) was $15 \mathrm{~m}$ southeast from the injection well. 
Table 3.2. Field Site Monitoring Locations

\begin{tabular}{cc}
\hline $\begin{array}{c}\text { Monitoring } \\
\text { Location }\end{array}$ & $\begin{array}{c}\text { Distance from } \\
\text { Injection Well (m) }\end{array}$ \\
\hline C7526-S & 2.33 \\
C7529-L & 1.85 \\
C7524-S & 2.28 \\
C7527-L & 2.04 \\
C7528-S & 2.43 \\
C7531-L & 2.62 \\
C7522-S & 2.68 \\
C7523-L & 3.02 \\
C7525-L & 3.02 \\
C7530-S & 3.67 \\
C7533-L & 4.18 \\
C7534-S & 5.79 \\
C7537-L & 5.34 \\
C7532-S & 5.22 \\
C7535-L & 6.18 \\
C7536-S & 8.49 \\
C7539-L & 8.64 \\
C7538-S & 14.96 \\
C7541-L & 14.94 \\
\hline An "S" designation is for boreholes that contained in \\
situ sensors. An "L" designation is for cased wells \\
that were used for logging access. \\
\hline
\end{tabular}

\subsubsection{Borehole Sensor Descriptions}

Thermistors (USP8242 encapsulated negative temperature coefficient thermistors, U.S. Sensor, Orange, California) were used to monitor temperature. To achieve accurate temperature measurements over the range of interest, a fifth-order polynomial was used to relate resistance to temperature for each of the thermistors used in the field test. The manufacturer's calibration relationship was verified for a subset of the thermistors in a precision water bath spanning the $0^{\circ} \mathrm{C}-40^{\circ} \mathrm{C}$ temperature range with measured accuracies better than $0.07^{\circ} \mathrm{C}$.

Temperatures were logged continuously (10-min intervals) at each thermistor. In addition to providing important information concerning desiccation progress, the temperature field data are also used to correct the ERT-derived electrical conductivity to a standard temperature prior to using the ERT data for estimating volumetric water content.

Matric potential data were collected using Heat Dissipation Unit (HDU) sensors (229-L HDU, Campbell Scientific, Inc., Logan, Utah) to indirectly determine the air-water capillary pressure. A 50-mA current excitation module was used to supply current to the HDU sensors. The HDU temperature was measured prior to heating and again at $1 \mathrm{~s}$ and $30 \mathrm{~s}$ after the onset of heating; these values were used to compute the associated matric potential (Oostrom et al. 2012a). The measurement range of the units is typically from -0.01 to $-2.5 \mathrm{MPa}(-0.1$ to -25 bar) with an accuracy of $1 \mathrm{kPa}$ (Flint et al. 2002). The procedure described by Bilskie et al. (2007) was used for HDU calibration, which simplifies the extended 
procedure presented by Flint et al. (2002) by only requiring calibration data in the range up to - $70 \mathrm{kPa}$. Once installed, the sand zones containing the HDU sensors were allowed to equilibrate with the conditions in the native formation before the injection operations were initiated.

Soil gas relative humidity was monitored using a CS215 capacitive relative humidity and temperature sensor (Campbell Scientific, Inc., Logan, Utah) with the electronics integral to the unit. The signal excitation and measurement are all completed within the device, followed by a conversion to a digital signal that can be monitored remotely. The sensing element is housed within a sintered high-density polyethylene filter to protect it from impact and environmental conditions. Each humidity probe is factory calibrated and the accuracy of the device is $2 \%$ within the $10 \%$ to $90 \%$ relative humidity range and $4 \%$ from $0 \%$ to $100 \%$ relative humidity.

Borehole sensors also included Thermocouple Psychrometer (TCP) units (PST-55, Wescor Inc., Logan, Utah) and Dual-Probe Heat Pulse sensors (Specific Heat Sensors, East 30 Sensors, Pullman, Washington), but these sensors were not tracked during the rewetting period due to poor responses and sensor failures observed during the active desiccation phase (Truex et al. 2012a).

\subsubsection{Neutron Moisture Logging Measurements}

Neutron moisture logging was conducted using a CPN 503DR Hydroprobe (InstroTek Inc., Raleigh, North Carolina). Neutron probe measurements were acquired at depth increments of approximately $7.5 \mathrm{~cm}$ using a count time of $30 \mathrm{~s}$ and then converted to count ratio $\left(\mathrm{C}_{\mathrm{R}}\right)$ by dividing each measurement by the standard count. For the desiccation field test, neutron probes were deployed periodically in wells at the site to collect neutron moisture logs with data at discrete depth intervals in the subsurface.

Neutron probe data were converted to volumetric moisture content using a site-specific relationship that was developed from core measurements of gravimetric moisture content and bulk density (full description provided by Truex et al. [2012a]). In summary, core samples were collected adjacent to logging location $\mathrm{C} 7527$ after the active desiccation phase of the test. Neutron moisture probe $\mathrm{C}_{\mathrm{R}}$ data were plotted with corresponding post-desiccation laboratory-measured volumetric moisture content (computed using measured gravimetric moisture content and bulk density) from samples at the same depth, laterally within $0.9 \mathrm{~m}$ of the neutron logging well (Figure 3.7). Assuming that soil moisture content values are not substantially different at that lateral distance from the logging well, the laboratory data were used to establish a calibration for the neutron moisture probe data. Regression of volumetric moisture content $(\theta)$ (see Truex et al. 2012a) and $C_{R}$ data for all core samples resulted in the relationship $\theta=0.714 C_{R}^{2}-0.1363 C_{R}$, with a root mean square error of 0.015 for $\theta$ and a coefficient of determination of 0.93 . 


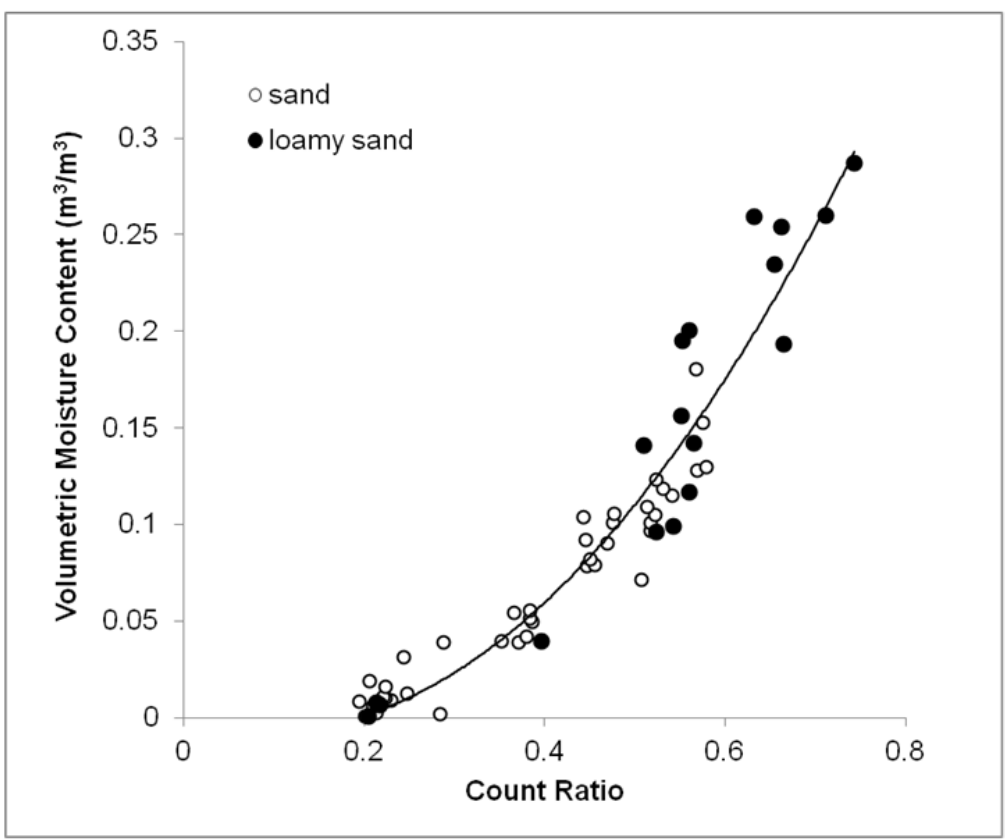

Figure 3.7. Calibration Relation for Neutron Moisture Probe Count Ratio Data and Corresponding Laboratory-Measured Volumetric Moisture Content

\subsubsection{Cross-Hole Electrical Resistivity Measurements}

ERT is a method of remotely imaging the electrical conductivity (EC) of the subsurface. Electrodes installed along the ground surface and/or within boreholes are used to strategically inject currents and measure the resulting potentials to produce a data set that is used to reconstruct the subsurface EC structure (Daily and Owen 1991; Johnson et al. 2010). With respect to soil desiccation, EC is a useful metric for characterizing the subsurface because it is governed by properties that influence gas flow, including soil texture and moisture content. EC is also a useful metric for monitoring desiccation because it is sensitive to moisture content and temperature (Slater and Lesmes 2002), the two primary properties altered during desiccation.

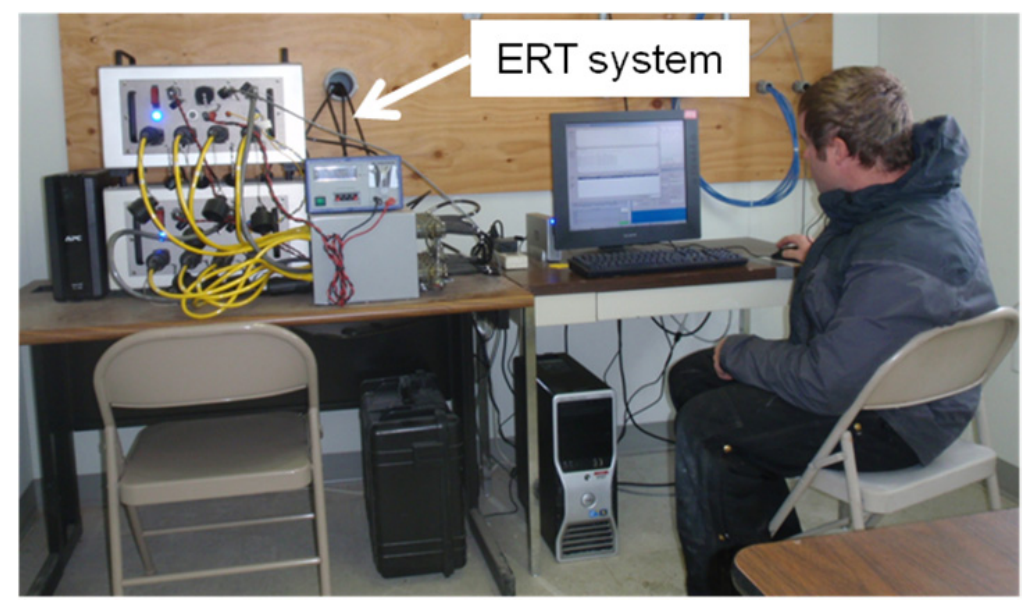

Control System for Electrical Resistivity Tomography
The ERT electrode array deployed in this study was first used to characterize pre-desiccation subsurface structure, providing important 3D information regarding permeability and likely gas flow pathways. During desiccation, the same array was used to image 3D changes in EC from background caused primarily by decreasing moisture content but also by evaporative cooling. ERT surveys were collected twice per day during the desiccation phase, and weekly 
during the post-desiccation phase. The resulting changes in EC were temperature-corrected and converted to changes in moisture content using a site-specific laboratory-validated relationship (Archie 1942). Results of pre-desiccation and desiccation ERT monitoring are provided by Truex et al. (2012a, 2013).

For the previously reported pre-desiccation and active desiccation test phases and for the postdesiccation test phase reported herein, ERT data were collected using 99 electrodes - 11 electrodes in each of the 9 sensor wells. Full forward and reciprocal measurements were collected to estimate data noise and quality, and each data set contained 6114 measurements after filtering. Measurements were collected using an 8-channel MPT DAS-1 impedance tomography system. ${ }^{1}$ These data were inverted with isotropic regularization smoothing constraints on an unstructured tetrahedral mesh with 354,544 elements using the imaging software described by Johnson et al. (2010). The EC data collected from the ERT system provide a means to image changes in the volumetric moisture content over time in three dimensions.

\subsubsection{Cross-Hole Ground Penetrating Radar Measurements}

GPR methods are also commonly used to characterize or monitor subsurface moisture content. GPR systems consist of an impulse generator that repeatedly sends a particular voltage and frequency source to a transmitting antenna. Cross-hole GPR methods involve lowering a transmitter into a wellbore and measuring the energy with a receiving antenna that is lowered down another wellbore, and moving the transmitting and receiving antennae manually to different positions in the wellbores to facilitate transmission of the energy through a large fraction of the targeted area.

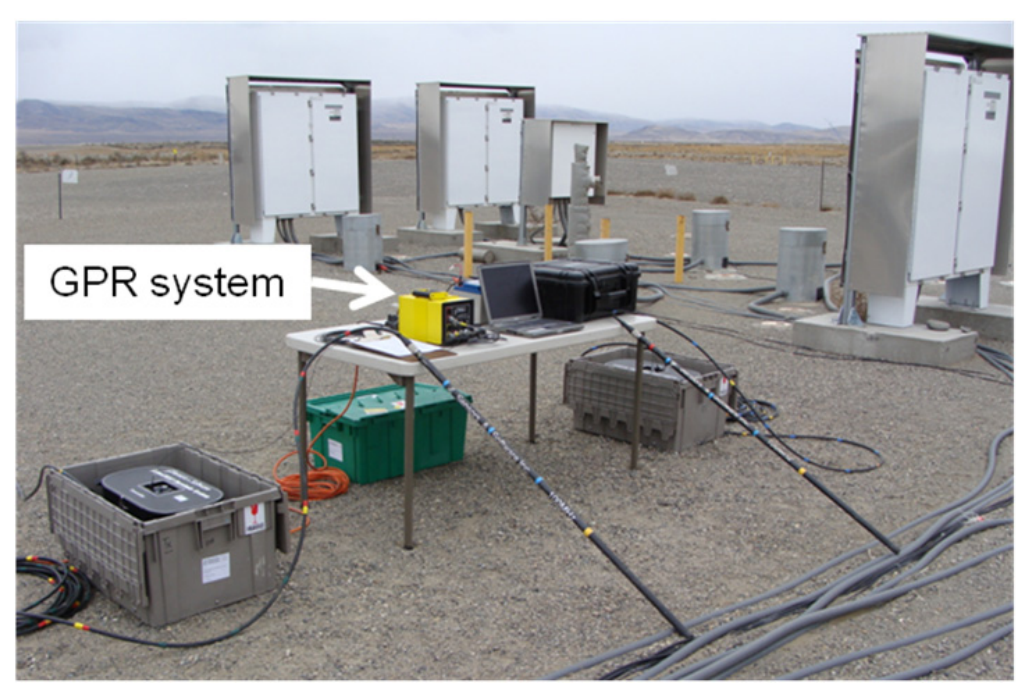

Ground Penetrating Radar Data Collection Equipment

Soil electrical permittivity is strongly dependent on moisture content because of the large difference between water and bulk soil permittivity. The relative permittivity of water is approximately 80 , compared to values between 3 and 7 for typical soil mineral components. The permittivity can be determined from the observed velocity of an electromagnetic pulse propagating through the soil matrix. Studies have demonstrated that GPR methods can effectively estimate subsurface moisture content using measured electromagnetic velocities (Hubbard et al. 1997; Van Overmeeren et al.

1997; Huisman et al. 2001). In general the electromagnetic velocity depends on both the permittivity and conductivity; however, when the conductivity is sufficiently low (i.e., low-loss conditions), GPR-derived velocities can be used to accurately determine permittivity and therefore moisture content.

\footnotetext{
${ }^{1} \mathrm{http}: / /$ www.mpt3d.com/.
} 
At the desiccation site, cross-borehole GPR surveys were conducted with the transmitting and receiving antennae placed in separate boreholes to measure the electromagnetic velocity between boreholes. Using measurements acquired from antennae located at many different vertical positions within each borehole, a two-dimensional (2D) image of properties between boreholes can be produced (Jackson and Tweeton 1994). These images can provide information that can be interpreted with respect to the geologic structure and moisture content between boreholes (Binley et. al 2002; Day-Lewis et al. 2002). For the desiccation field test, $2 \mathrm{D}$ images of electromagnetic velocity were generated with GPR and converted to volumetric moisture content changes using an established petrophysical relationship assuming low-loss conditions (Topp and Ferré 2002; Evett 2005). At the desiccation site, the electrical conductivity varies between 0 and $0.250 \mathrm{~S} / \mathrm{m}$ and the low-loss assumption is not valid at all locations. Thus, GPR data are analyzed and interpreted in conjunction with the subsurface EC data provided by the ERT system.

GPR data were collected with a PulseEKKO 100 using 100-MHz borehole antennae (Sensors and Software, Inc. Missasauga, Ontario, Canada). Multiple offset gather surveys were periodically collected in a set of four logging well pairs (using locations C7523, C7531, C7537, C7539, and the injection well). From these data, 2D electromagnetic velocity images were constructed using MIGRATOM, a curved ray inversion software (Jackson and Tweeton 1994).

\subsubsection{Data Collection System}

Sensor data for the field test were collected using CR3000 data loggers (Campbell Scientific Inc., Logan, Utah). Data were continuously and automatically retrieved from the data loggers and stored on a Dell T3400 computer located at the field site. A Raven X cellular phone modem (Sierra Wireless, Richmond, British Columbia, Canada) was installed to allow for remote monitoring of the data acquisition system and data transfer.

\subsubsection{Data Management}

Data from sensors were maintained on both data loggers and an onsite computer and were backed up periodically to an office computer. Sensor data were imported to spreadsheets at least twice per month

during active desiccation and every 3 months during the rewetting phase. The spreadsheets were used to convert raw sensor data to the required outputs, to plot results, and to serve as an additional data storage file for the plotted data. Manual test logs were maintained to document primary test events and for operations where no electronic sensor was available (e.g., condensate collection). The electronic and manual data are stored as part of project records and are documented in project reports. 


\subsection{Post-Desiccation Monitoring Results}

The results of the field test are presented in the next two sections. First, the results from sensors and geophysical monitoring are presented in Section 4.1. The data are then assessed with respect to the field test objectives in Section 4.2.

\subsection{Field Data Summary}

Post-desiccation monitoring was conducted to collect data to quantify the stability of the desiccated zone (i.e., the rate of rewetting) and to evaluate the field performance of monitoring instruments. The sections below present the data with respect to each of these basic field test elements.

\subsubsection{Post-Desiccation Data}

The three primary types of monitoring - in situ sensor monitoring, neutron moisture logging, and GPR surveying - for the rewetting period (July 2011 through August 2013) are discussed in the sections below for sensor, neutron, and geophysical data.

\subsubsection{Sensor Data}

In situ sensor monitoring was continued without interruption after active desiccation was terminated. The figures below (Figure 4.1 through Figure 4.8) show the responses for the sensor locations where a response was observed during active desiccation.

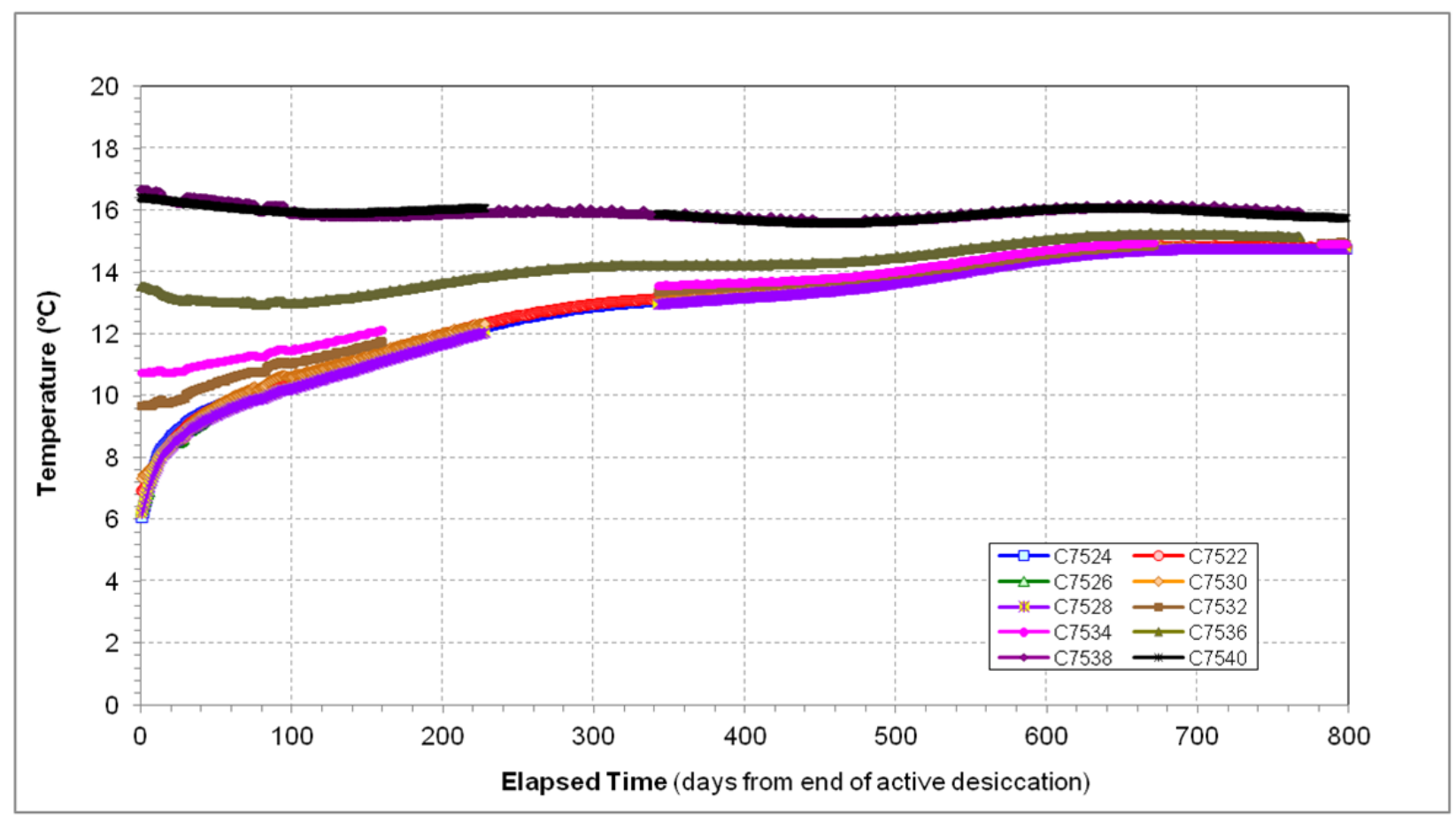

Figure 4.1. Post-Desiccation Temperature Response over Time for the Sensors at a Depth of $32.5 \mathrm{ft}$ $(9.9 \mathrm{~m})$ bgs 


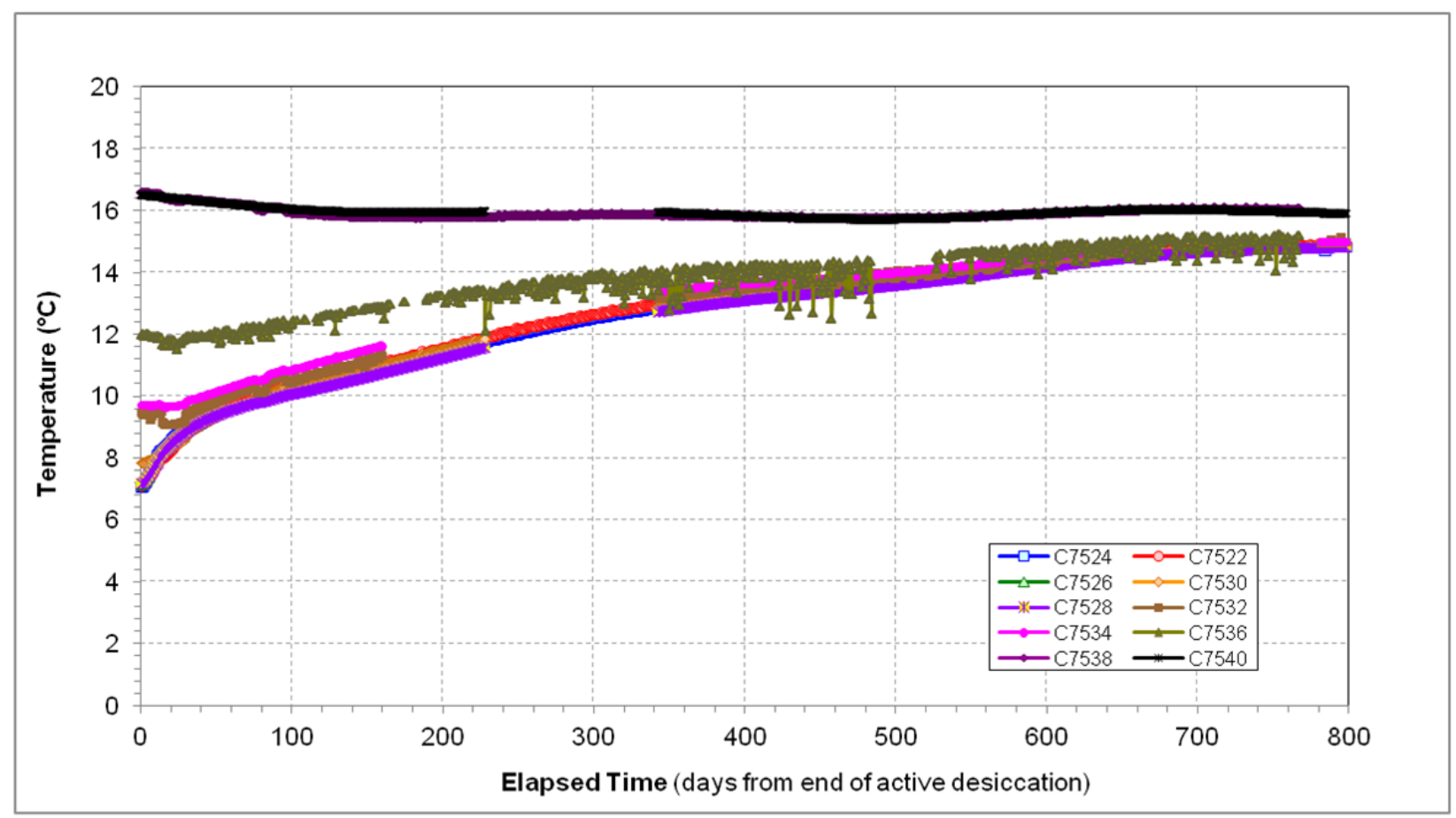

Figure 4.2. Post-Desiccation Temperature Response over Time for the Sensors at a Depth of $36.5 \mathrm{ft}$ (11.1 m) bgs

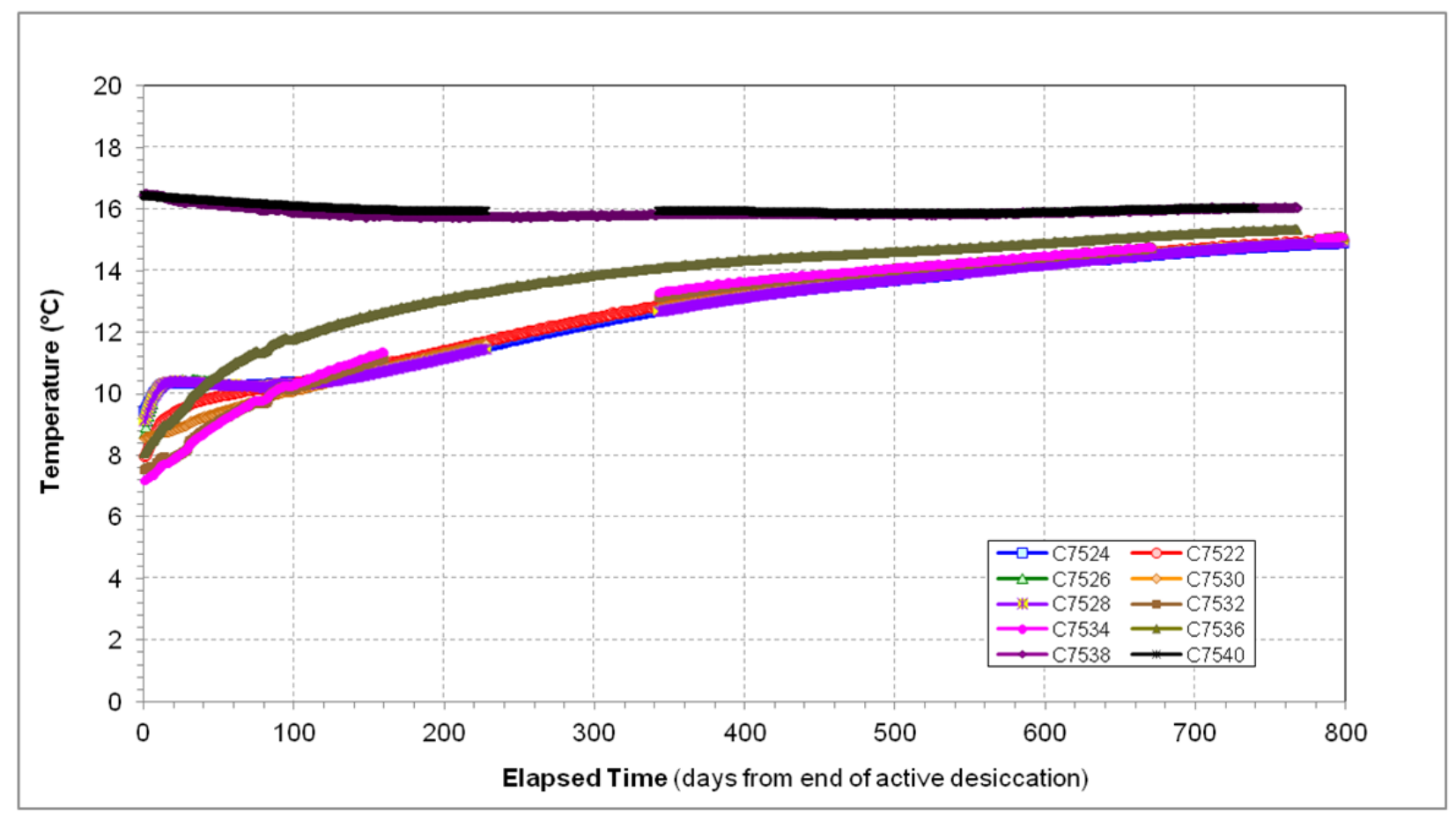

Figure 4.3. Post-Desiccation Temperature Response over Time for the Sensors at a Depth of $42.5 \mathrm{ft}$ (13 m) bgs 


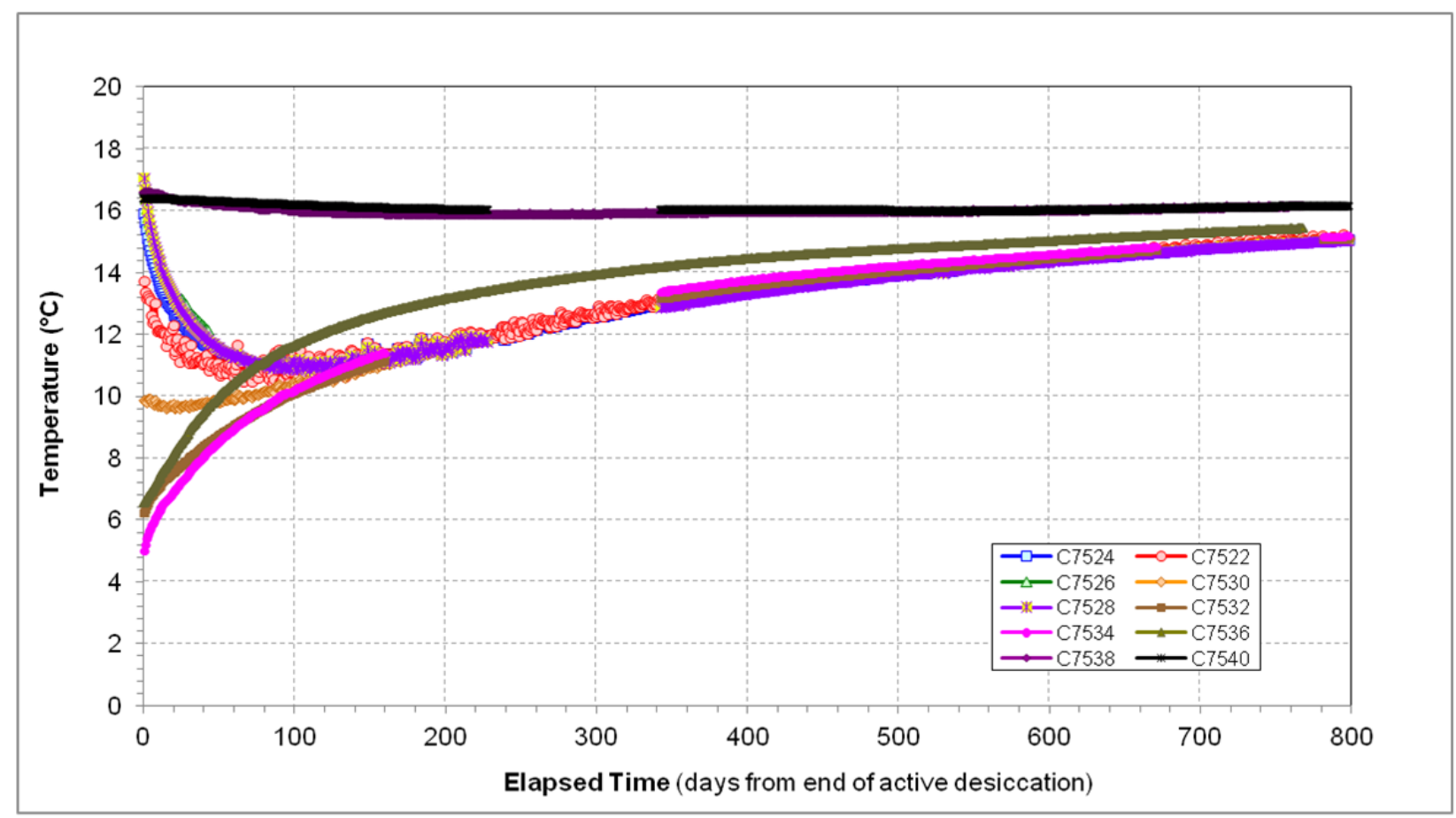

Figure 4.4. Post-Desiccation Temperature Response over Time for the Sensors at a Depth of $46.5 \mathrm{ft}$ $(14.2 \mathrm{~m}) \mathrm{bgs}$

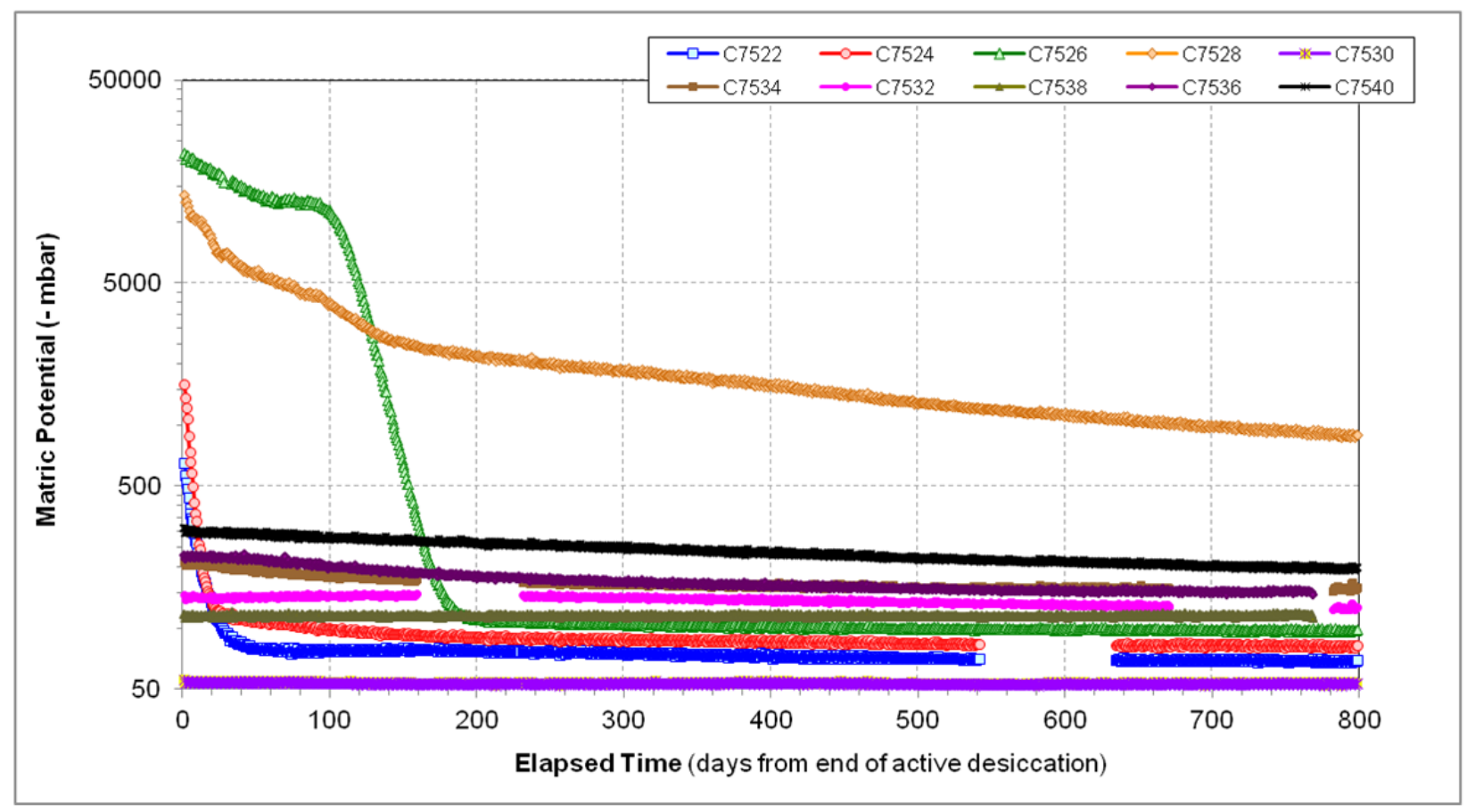

Figure 4.5. Post-Desiccation Heat Dissipation Unit (matric potential) Response over Time for the Sensors at a Depth of $42.5 \mathrm{ft}(13 \mathrm{~m})$ bgs. Note that the y-axis uses a logarithmic scale. 


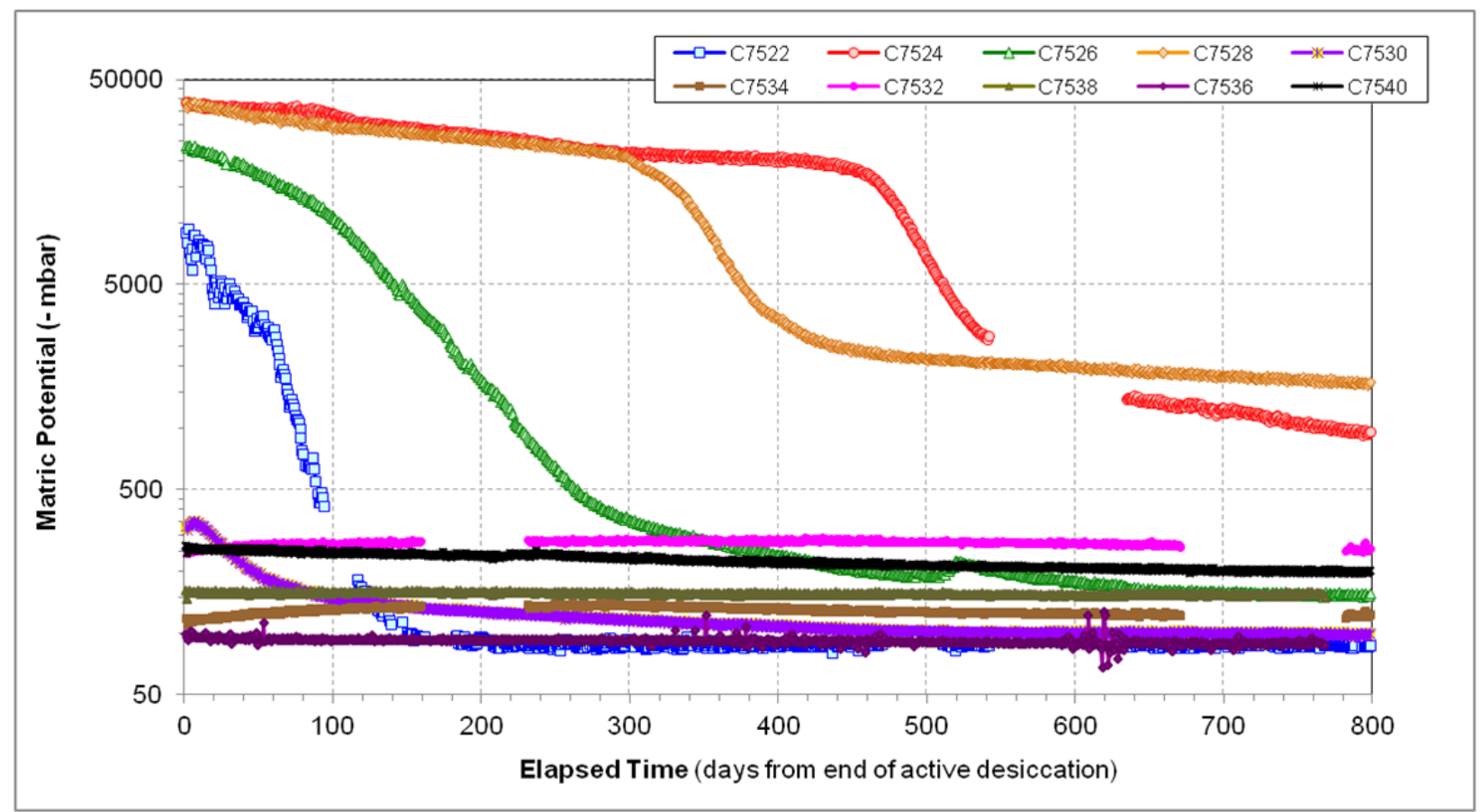

Figure 4.6. Post-Desiccation Heat Dissipation Unit (matric potential) Response over Time for the Sensors at a Depth of $47.5 \mathrm{ft}(14.5 \mathrm{~m})$ bgs. Note that the y-axis uses a logarithmic scale.

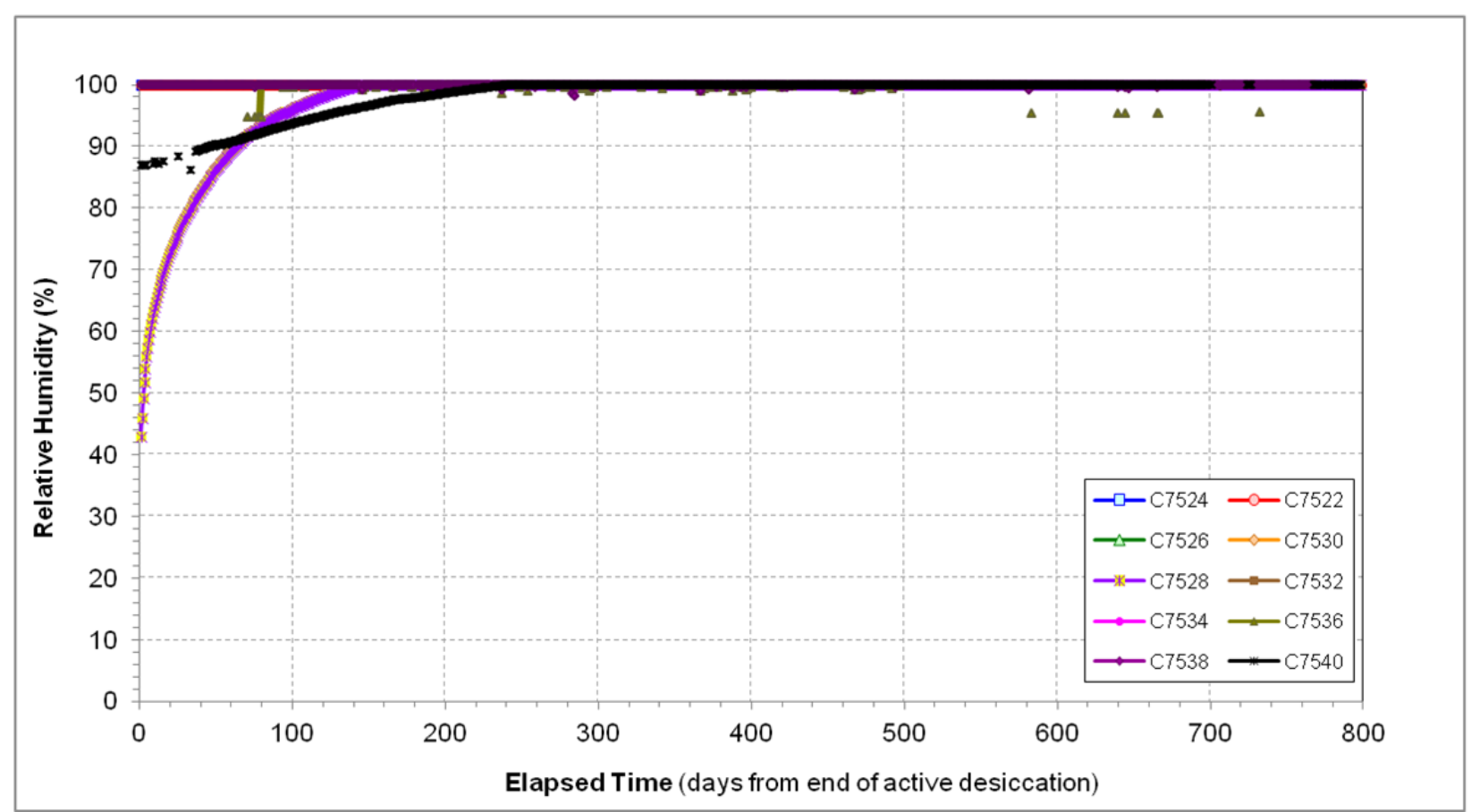

Figure 4.7. Post-Desiccation Relative Humidity Probe Response over Time for the Sensors at a Depth of $42.5 \mathrm{ft}(13 \mathrm{~m}) \mathrm{bgs}$ 


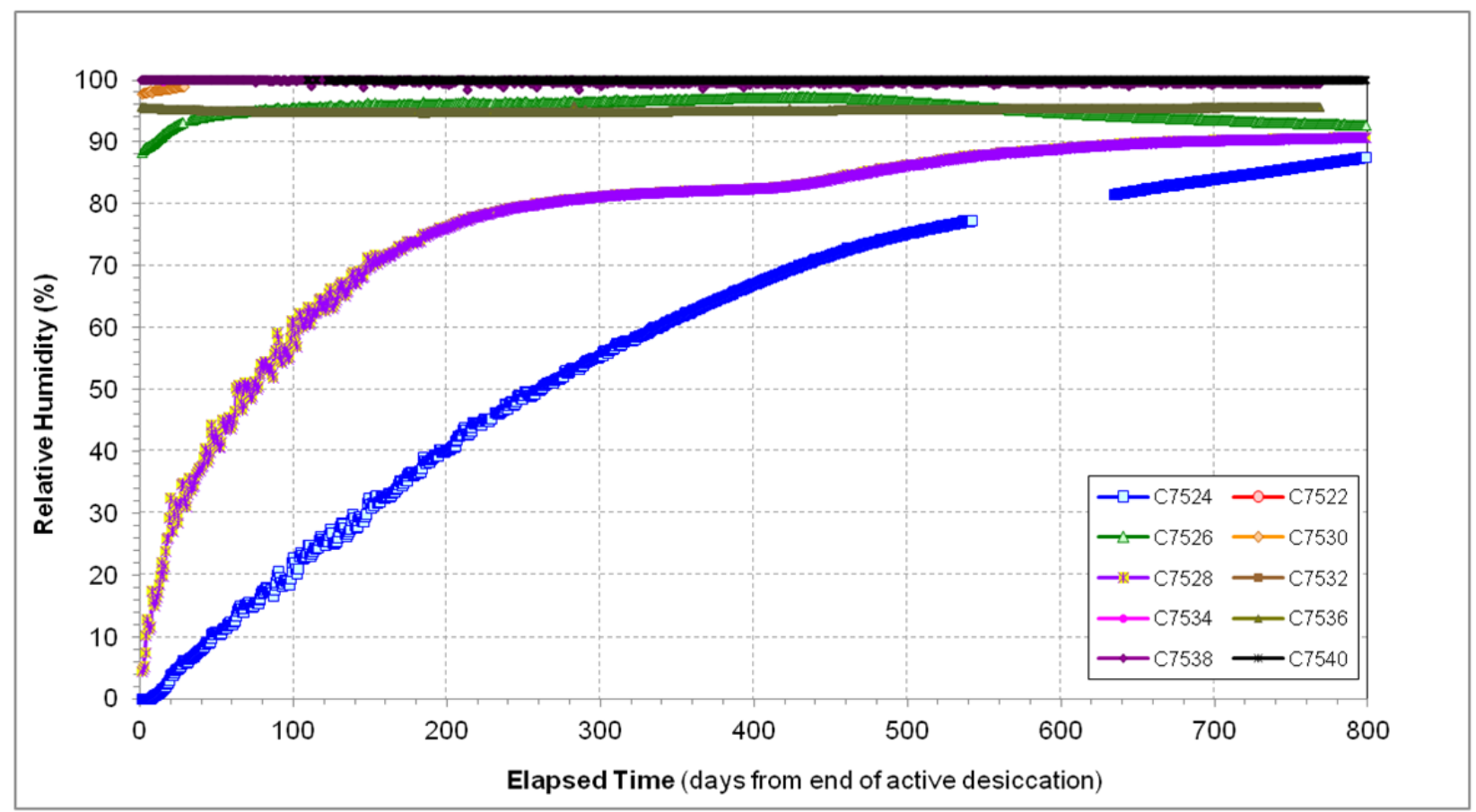

Figure 4.8. Post-Desiccation Relative Humidity Probe Response over Time for the Sensors at a Depth of $47.5 \mathrm{ft}(14.5 \mathrm{~m}) \mathrm{bgs}$

Temperatures at the key depths of 32.5, 36.5, 42.5, and $46.5 \mathrm{ft}$ bgs have continued a gradual increase at locations near the injection well and are now within about $1{ }^{\circ} \mathrm{C}$ of the temperatures at distant/background locations. Several locations (C7524, C7522, C7526, C7528, and, to some extent, C7530) had reached a state of higher temperatures at the $46.5-\mathrm{ft}(14.2-\mathrm{m})$ depth as a result of drying to the point where evaporative cooling was no longer occurring. In contrast, evaporative cooling was still occurring at locations C7532, C7534, and C7536, so those locations had low temperatures at the end of active desiccation operations. By about 100 days after active desiccation, temperatures at all locations for the 47.5-ft depth converged and proceeded to gradually increase over time.

Several locations at depths of 42.5 and $47.5 \mathrm{ft}(13$ and $14.5 \mathrm{~m})$ bgs had exhibited a significant change in matric potential (as measured with the heat dissipation unit sensors) to values between -5000 and -50000 mbar during desiccation, indicating that significant drying occurred. After the end of active desiccation, the matric potential returned to nominally the pre-desiccation levels for most locations that had indicated drying. At a depth of $42.5 \mathrm{ft}(13 \mathrm{~m})$ bgs, the matric potential at locations C7522 and C7524 returned to around -75 to -100 mbar in a fairly short time frame after the end of active desiccation. Matric potential at location C7526 shows a 100-day lag before a relatively rapid change from -13000 mbar to values near -100 mbar. At location $\mathrm{C} 7528$ for the 42.5 - $\mathrm{ft}$ depth, the matric potential indicated a more gradual rewetting, with conditions appearing to approach a stable state that is drier (at about $-900 \mathrm{mbar}$ ) than pre-desiccation conditions (about -180 mbar). At the deeper 47.5-ft (14.5-m) locations, matric potential indicated a somewhat slower rewetting. Location C7530, which was just beginning to show changes in matric potential indicative of drying at the end of active desiccation, quickly returned to predesiccation levels. Matric potential at $\mathrm{C} 7522$ also had a relatively quick (within about 100 days) return to pre-desiccation matric potential. The return to pre-desiccation matric potential at the $\mathrm{C} 7526$ location for 
the 47.5-ft depth was delayed and more gradual than observed by the corresponding sensor at the 42.5 - $\mathrm{ft}$ depth. Matric potential at the 47.5-ft depth at $\mathrm{C} 7528$ exhibited a similar gradual rewetting and appears to be approaching a stable state near -1600 mbar. At the $\mathrm{C} 7524$ location for the $47.5 \mathrm{ft}$ depth, unlike the $42.5 \mathrm{ft}$ depth, the matric potential showed rewetting after a much longer delay (about 450 days after the end of active desiccation) and a much more gradual rewetting that is currently near -900 mbar.

Several humidity sensors exhibited a transition to low relative humidity during active desiccation operation, indicating that drying was occurring. After the end of active desiccation, the lower relative humidity at a depth of $42.5 \mathrm{ft}(13 \mathrm{~m})$ for the $\mathrm{C} 7528$ location showed a relatively prompt (within about 100 days after the end of active desiccation) return to $100 \%$ relative humidity. While the humidity at a depth of $42.5 \mathrm{ft}(13 \mathrm{~m})$ for the $\mathrm{C} 7540$ location (background sensor) appeared to show a recovery to $100 \%$ relative humidity, this probe had previously shown essentially constant readings of about $85-90 \%$ since installation, so its readings are not considered accurate indications of humidity at that location. Humidity sensors at the $47.5-\mathrm{ft}(14.5-\mathrm{m})$ depth for locations C7524 and C7528 have shown a much more gradual return to high humidity values. Only now, some 800 days after the end of active desiccation, have these two sensors reached values of $85-90 \%$ relative humidity. At the C7526 location for the 47.5-ft (14.5-m) depth, moderate decreases in humidity were observed near the end of the active desiccation period. The humidity quickly rebounded at this location, although the humidity values have drifted over time. Several of the humidity probes both during and after active desiccation have shown readings below $100 \%$ relative humidity when it was expected that the relative humidity should be $100 \%$. Thus, it is unclear whether these readings are accurate.

\subsubsection{Neutron Data}

Vertical profiles from neutron moisture logging events conducted in July 2011, August 2011, September 2011, December 2011, February 2012, May 2013, and August 2013 are plotted in the following figures (Figure 4.9 through Figure 4.15) to depict the relative rewetting that has occurred during this time frame. These data show a clear progression of rewetting, especially for thin desiccated zones adjacent to wetter zones. At the C7527 and C7529 monitoring locations, the thicker desiccated zones have shown the least rewetting. These neutron data are assessed in more detail in Section 4.2 with respect to rewetting rate. 


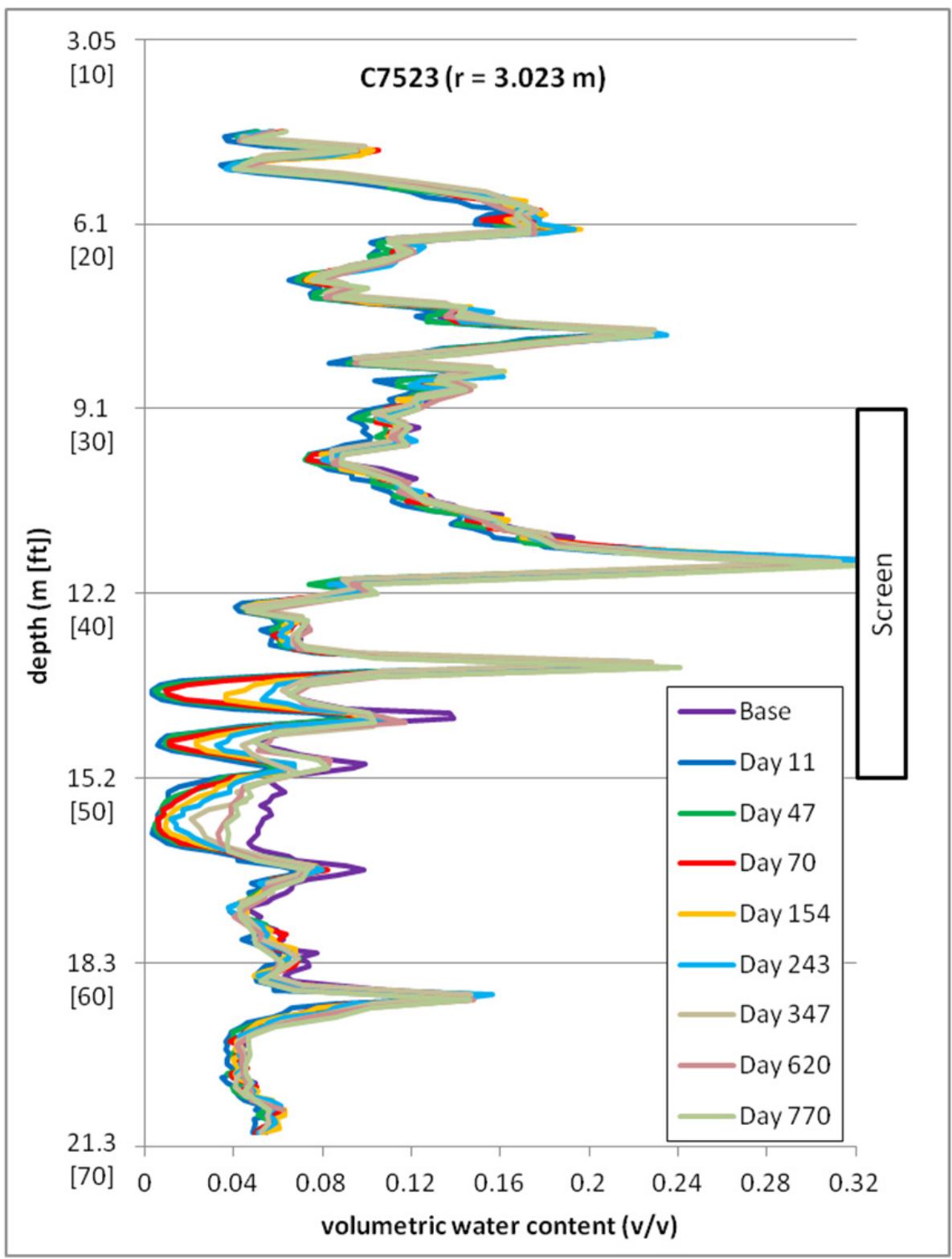

Figure 4.9. Neutron Moisture Probe Response over Time for Location C7523 (3.023 m from injection well). The base time is a logging event in December 2010, prior to the continuous active desiccation period. Other data are for logging events in nominal days after the end of active desiccation. 


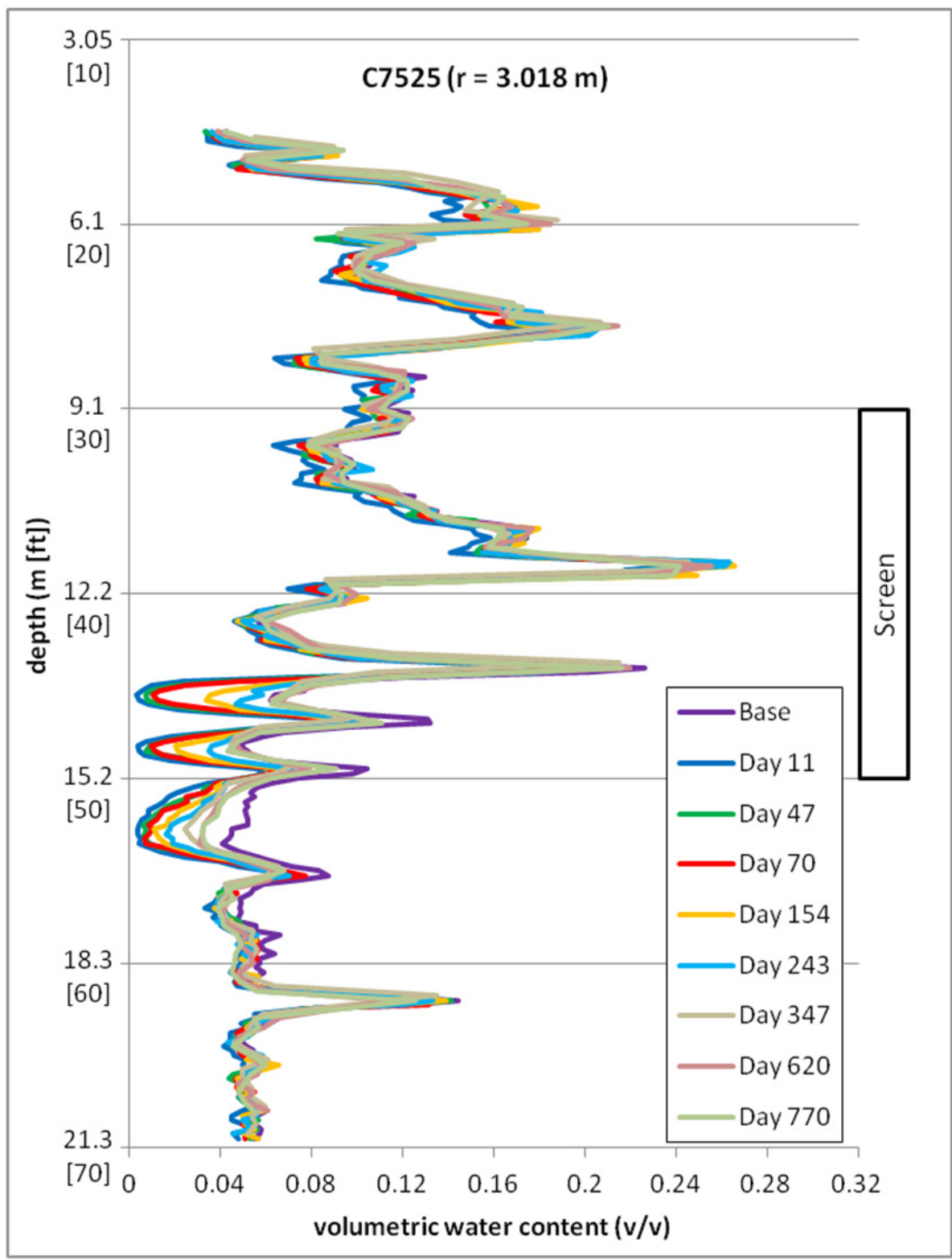

Figure 4.10. Neutron Moisture Probe Response over Time for Location C7525 (3.018 m from injection well). The base time is a logging event in December 2010, prior to the continuous active desiccation period. Other data are for logging events in nominal days after the end of active desiccation. 


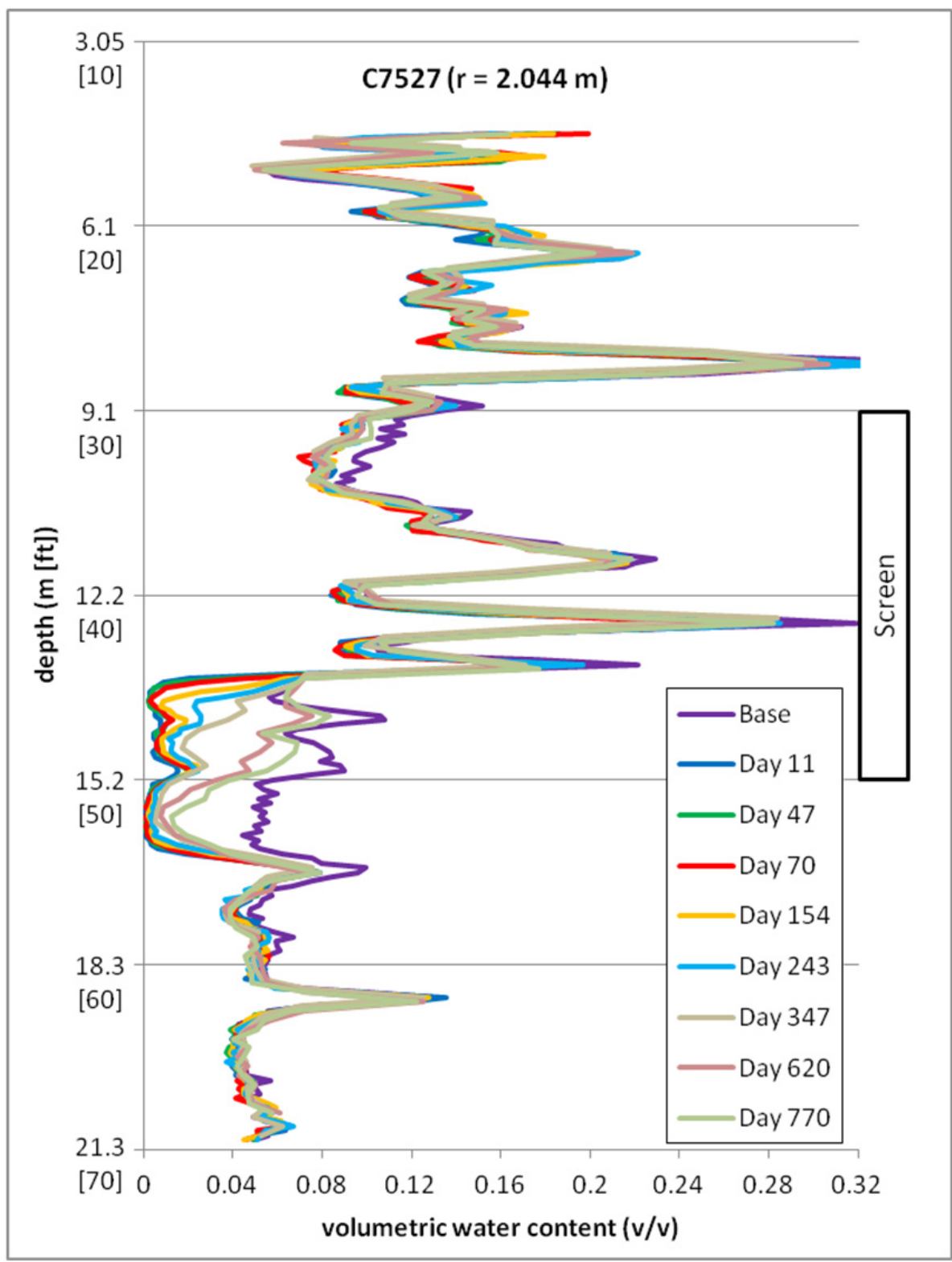

Figure 4.11. Neutron Moisture Probe Response over Time for Location C7527 (2.044 m from injection well). The base time is a logging event in December 2010, prior to the continuous active desiccation period. Other data are for logging events in nominal days after the end of active desiccation. 


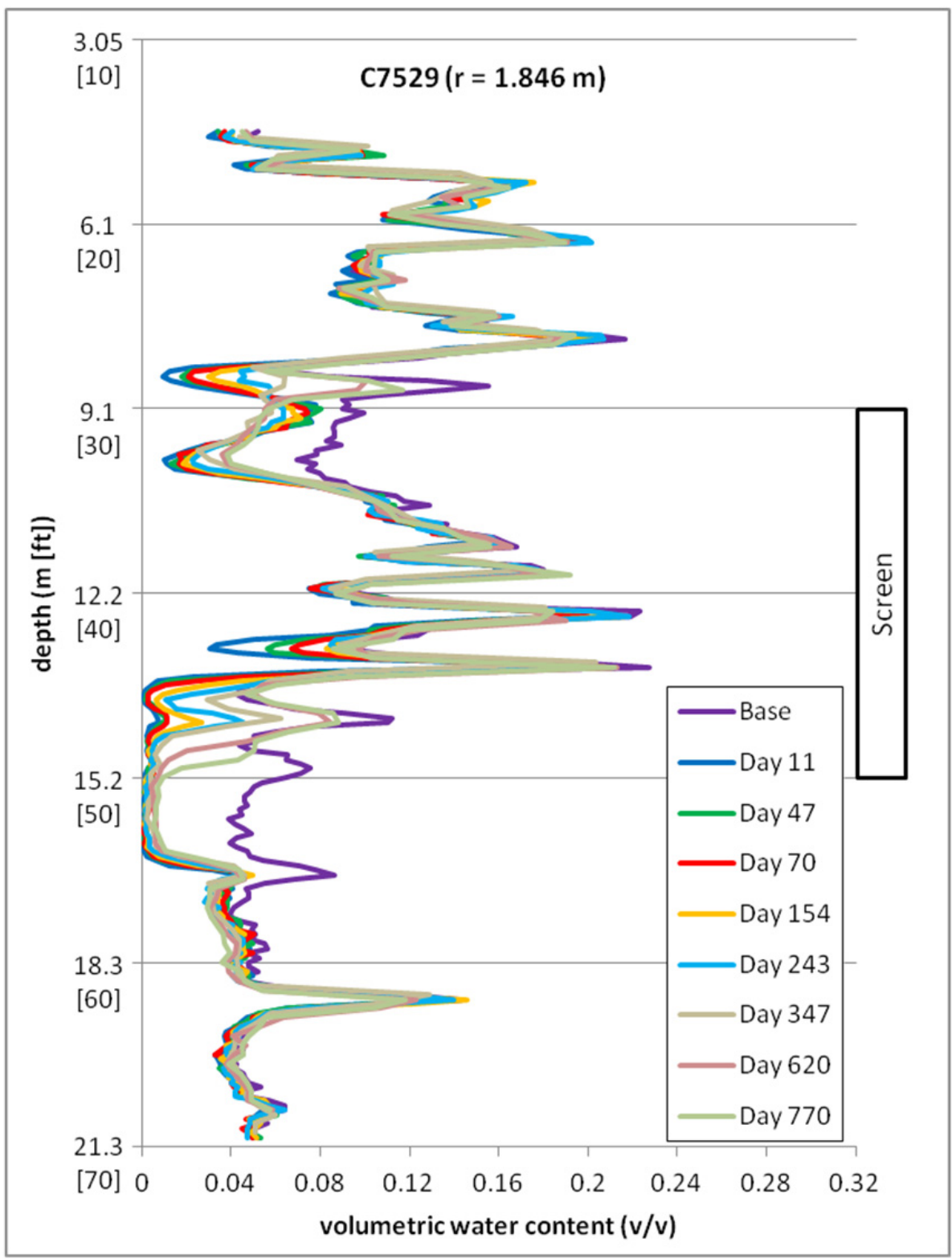

Figure 4.12. Neutron Moisture Probe Response over Time for Location C7529 (1.846 m from injection well). The base time is a logging event in December 2010, prior to the continuous active desiccation period. Other data are for logging events in nominal days after the end of active desiccation. 




Figure 4.13. Neutron Moisture Probe Response over Time for Location C7531 (2.620 m from injection well). This location is along the axis between the injection and extraction wells. The base time is a logging event in December 2010, prior to the continuous active desiccation period. Other data are for logging events in nominal days after the end of active desiccation. 


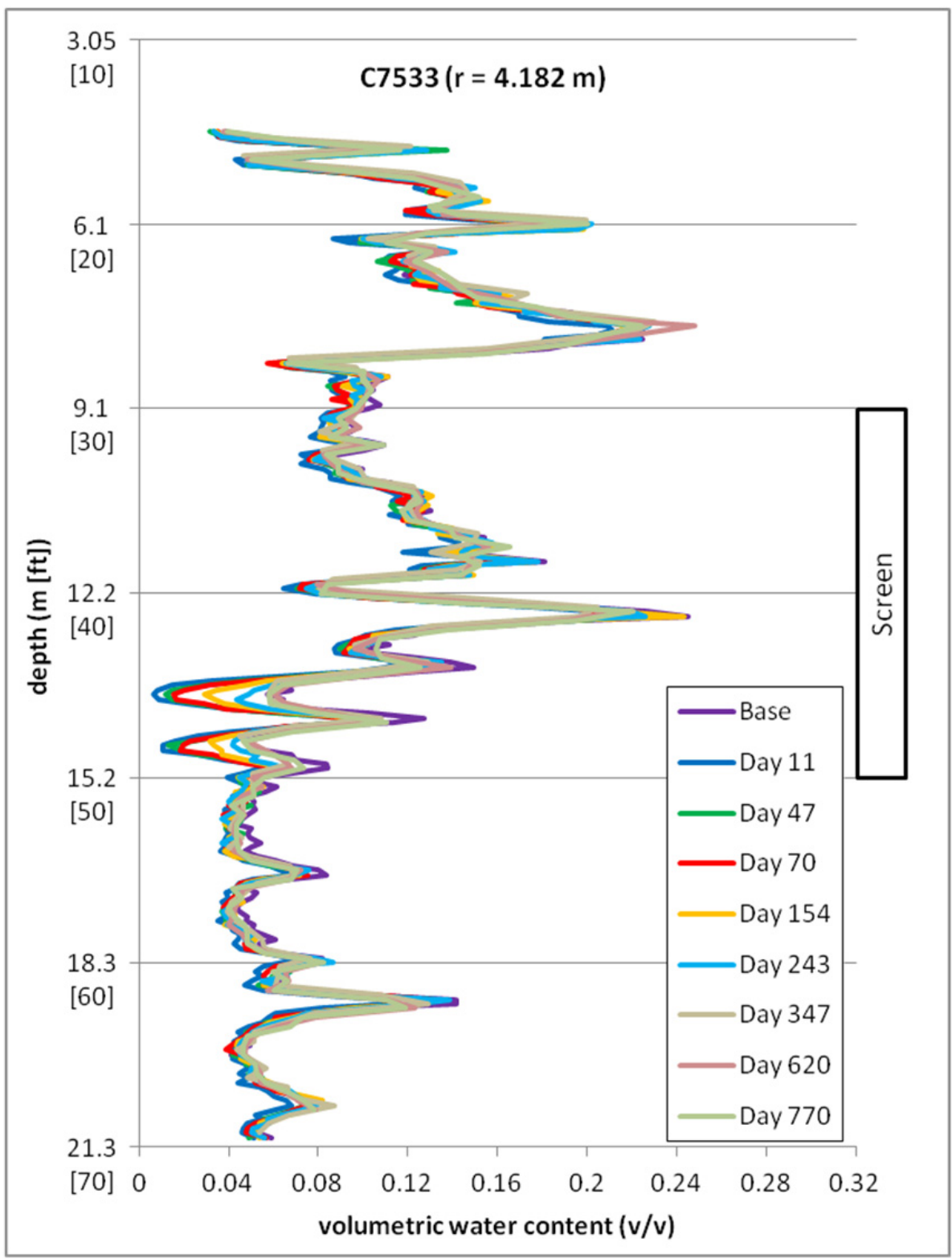

Figure 4.14. Neutron Moisture Probe Response over Time for Location C7533 (4.182 m from injection well). The base time is a logging event in December 2010, prior to the continuous active desiccation period. Other data are for logging events in nominal days after the end of active desiccation. 


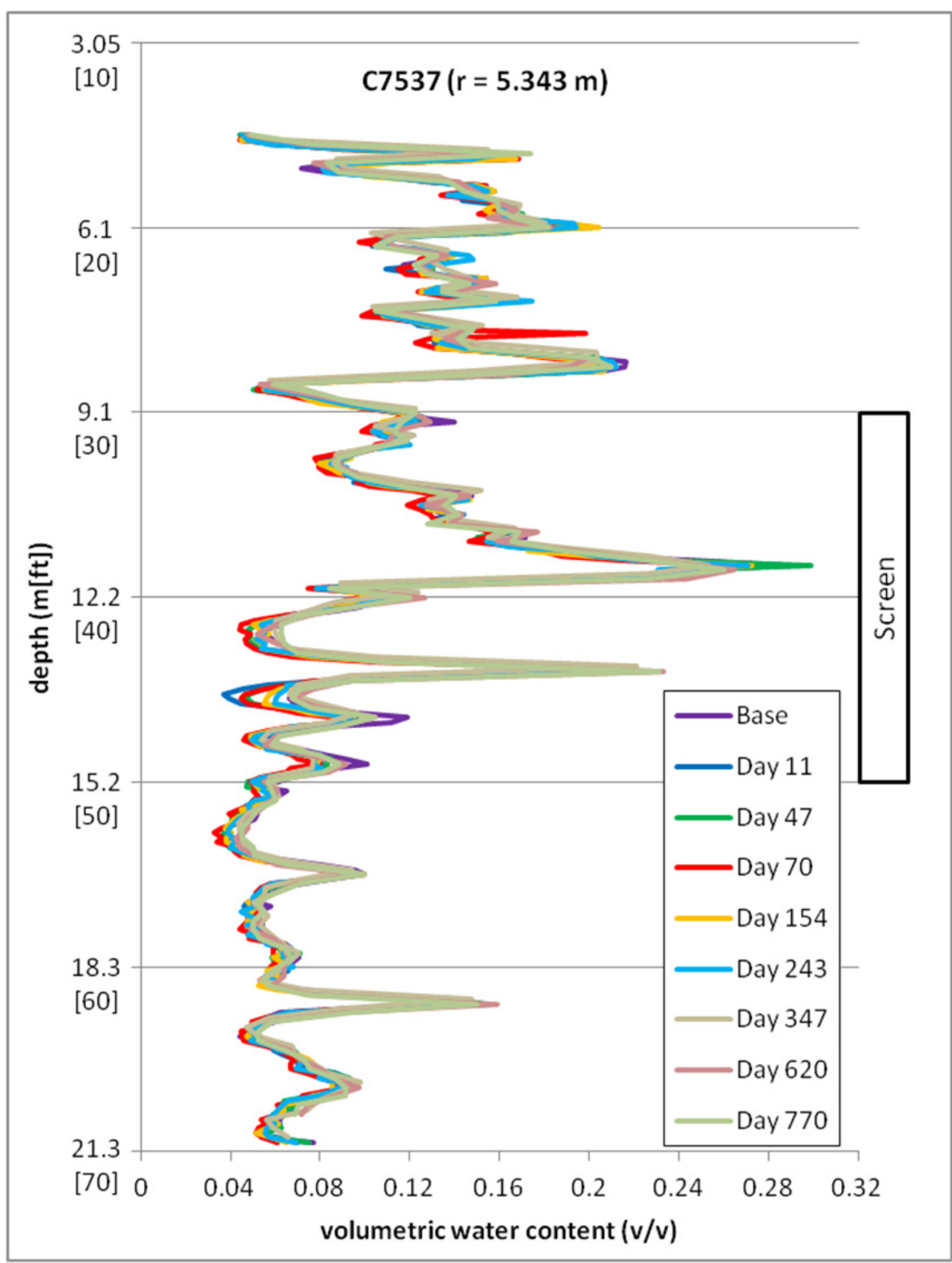

Figure 4.15. Neutron Moisture Probe Response over Time for Location C7537 (5.343 m from injection well). This location is along the axis between the injection and extraction wells. The base time is a logging event in December 2010, prior to the continuous active desiccation period. Other data are for logging events in nominal days after the end of active desiccation.

\subsubsection{Geophysical Data}

Periodic GPR survey data were collected during post-desiccation monitoring. The GPR-interpreted volumetric moisture content distribution at day 137 during active desiccation and days 193, 265, 650, and 770 after the end of active desiccation are shown in Figure 4.16. Note the GPR data at day 137 during desiccation are prior to the end of active desiccation (e.g., day 164) such that conditions were likely dryer at the onset of the post-desiccation monitoring period. The post-desiccation GPR data show a general 
increase in volumetric moisture content over time within the 2D survey cross section. In some areas, localized re-distribution of moisture has caused drying of some small zones as water moved to adjacent dryer zones. The GPR data indicate that the driest zones during desiccation near the injection well, including about $10 \mathrm{~m}$ bgs and about $15 \mathrm{~m}$ bgs, have remained the driest over time, although, within the resolution of the GPR analysis, they have increased in moisture content after the end of active desiccation. The GPR data show that moisture content within these portions of the survey cross section are still dryer than pre-desiccation conditions (Figure 4.17).
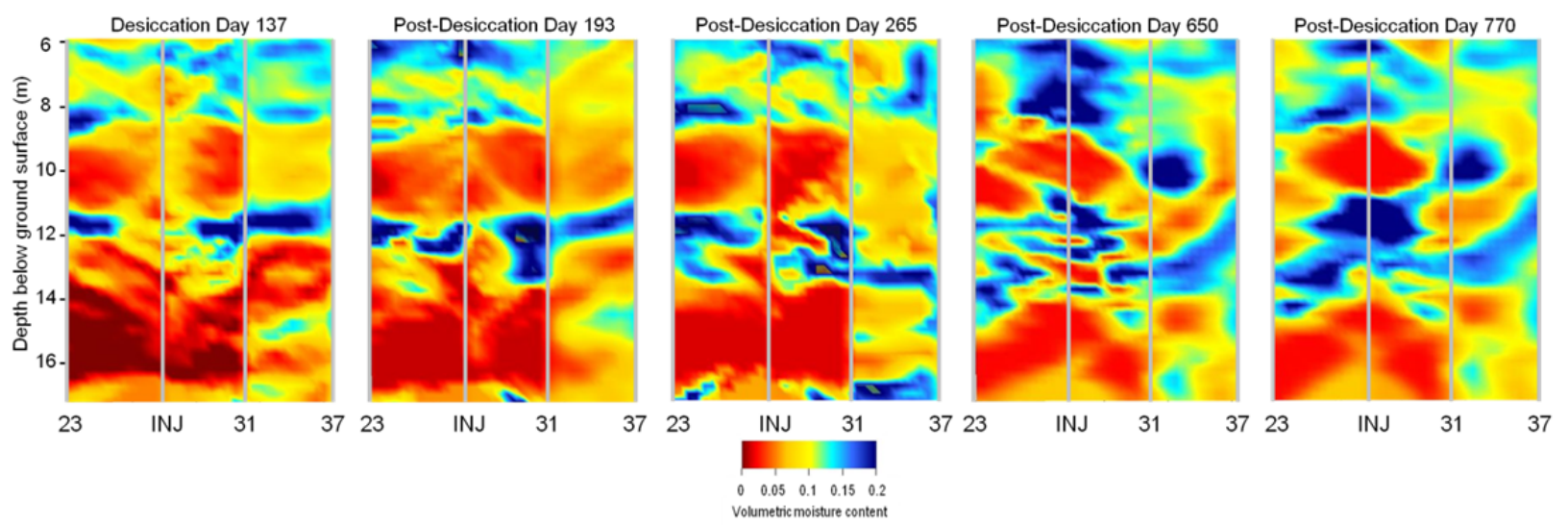

Figure 4.16. 2D Interpretation of Volumetric Moisture Content from Cross-Hole Ground Penetrating Radar Data during Desiccation (left) at Day 137 (June 3, 2011) and after the End of Active Desiccation (right) at Days 193 and 265. Locations are shown as INJ (injection well) and logging well locations are indicated by the last two numbers in the location identifier (e.g., $23=$ C7523).

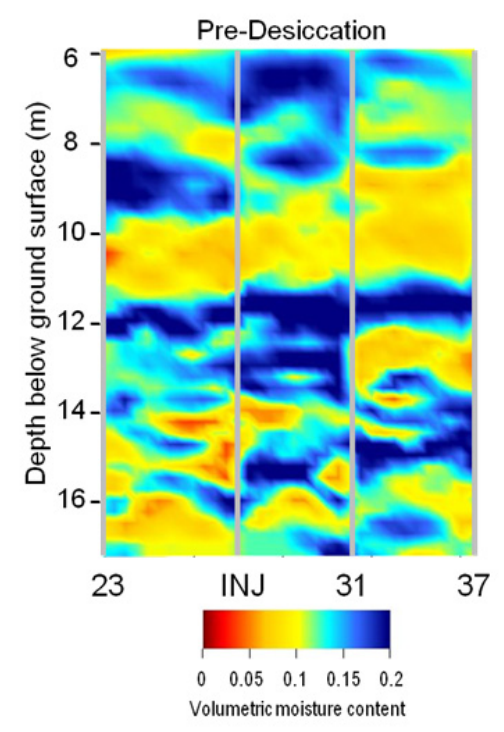

Figure 4.17. 2D Interpretation of Initial Volumetric Moisture Content from Cross-Hole Ground Penetrating Radar Data Prior to Desiccation. Locations are shown as INJ (injection well) and logging well locations are indicated by the last two numbers in the location identifier (e.g., $23=$ C7523). 
Interpretation of the 2D moisture content representation should consider that conversion of GPRderived permittivity to volumetric moisture content (VMC) is affected by EC. Desiccation reduces the EC, which renders GPR data acquisition more favorable within desiccated zones, and improves the accuracy of the GPR-derived moisture content estimate. For example, Figure 4.18 shows the ERTderived EC distribution along the GPR survey transect at the end of desiccation and at days 650 and 770 post-desiccation. The black regions illustrate where low EC, or low-loss, assumptions may not be valid (EC $>0.05 \mathrm{~S} / \mathrm{m})$. Prior to desiccation, the low-loss assumption was generally valid above a depth of $10 \mathrm{~m}$ and invalid below $10 \mathrm{~m}$. At the end of desiccation, low-conductivity conditions have been established within a zone from depths of approximately $13 \mathrm{~m}$ to $15 \mathrm{~m}$ (Figure 4.18). Within this depth interval, GPR-derived moisture content estimates correlated well with estimates from neutron moisture logging (Truex et al. 2012a). Within zones where desiccation has decreased the EC, GPR can be used with confidence to estimate the moisture content distribution between wells. At 650 days postdesiccation, low-loss conditions mostly remain within the $13-\mathrm{m}$ to $15-\mathrm{m}$ zone. However, by postdesiccation day 770, this zone appears to be recovering sufficiently such that low-loss conditions may no longer be applicable.
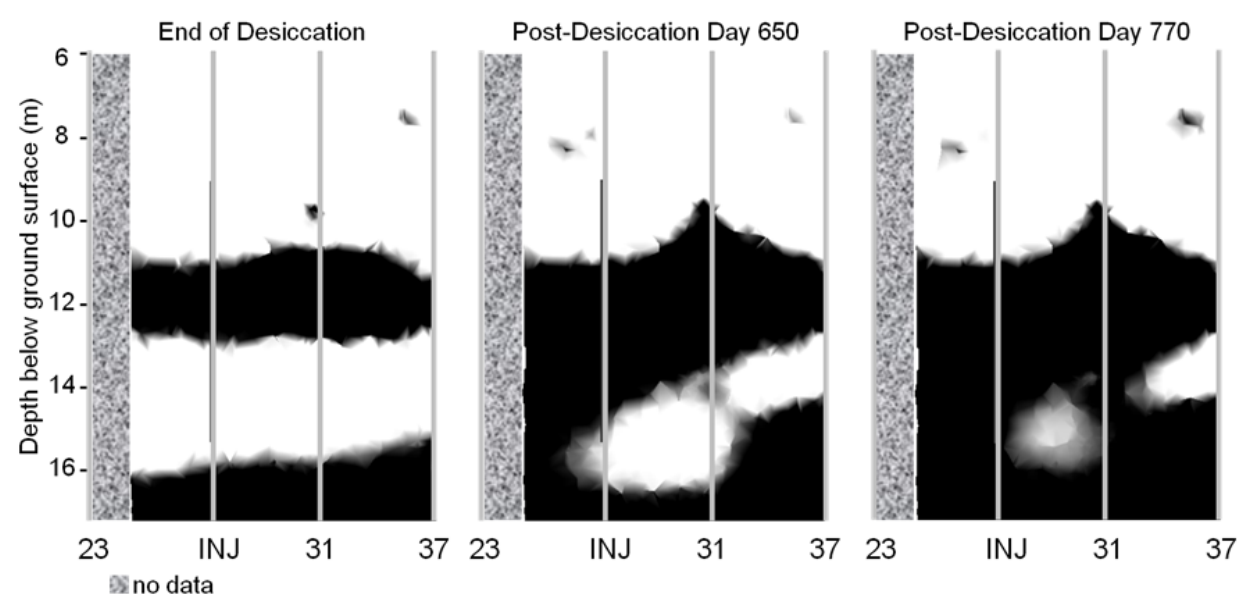

Figure 4.18. $2 \mathrm{D}$ image showing regions where GPR low-loss conditions (white) are valid resulting in higher confidence in GPR-derived moisture content estimates. From left to right: July 2012, April 2013, and September 2013. Locations are shown as INJ (injection well) and logging well locations are indicated by the last two numbers in the location identifier (e.g., $23=\mathrm{C} 7523$ ).

ERT monitoring was continued without interruption after active desiccation was terminated.

Figure 4.19 (first 270 days post-desiccation) and Figure 4.20 (650 and 770 days post-desiccation), show the ERT interpretation of changes in the VMC expressed as the ratio of VMC at the time of the measurement to the $\mathrm{VMC}$ at the end of active desiccation $\left(\mathrm{VMC}_{0}\right)$. A ratio of 1 designates areas that have not changed from the conditions at the end of active desiccation. Ratios higher than 1 indicate rewetting; for instance, a ratio of 3 means that the volumetric moisture content is 3 times higher than it was at the end of active desiccation. Ratios lower than 1 indicate drying; for instance, a ratio of 0.75 means that the VMC is 0.75 times what it was at the end of active desiccation. Note that the scales on Figure 4.19 and Figure 4.20 are different because the range of moisture changes has increased over time. The resolution of the ERT data inversion is on the order of a cubic meter. Thus, the ERT images cannot show sharp contrasts in wetting or drying zones over time, but show a "smoothed" image of how the subsurface is 
changing. In Figure 4.19, the image at day 116 of the post-desiccation period shows little change. As time progresses, some regions in the test area get wetter (proceeding from green to yellow to orange in color). At post-desiccation days 650 and 770 within the zone from $13 \mathrm{~m}$ to $15 \mathrm{~m}$ surrounding the injection well, continued rewetting can be observed with a maximum moisture content ratio of between 3 and 4 (Figure 4.20). At the end of desiccation the $\mathrm{VMC}$ in this zone was between $0.005 \mathrm{~m} / \mathrm{m}^{3}$ and $0.01 \mathrm{~m}^{3} / \mathrm{m}^{3}$. With the observed moisture content increase, the day $770 \mathrm{VMC}$ would be between $0.01 \mathrm{~m}^{3} / \mathrm{m}^{3}$ and $0.04 \mathrm{~m}^{3} / \mathrm{m}^{3}$, which is consistent with the information derived from neutron moisture and GPR data. The moisture for rewetting is being drawn from adjacent regions as shown by areas that have become dryer (darker blue color).

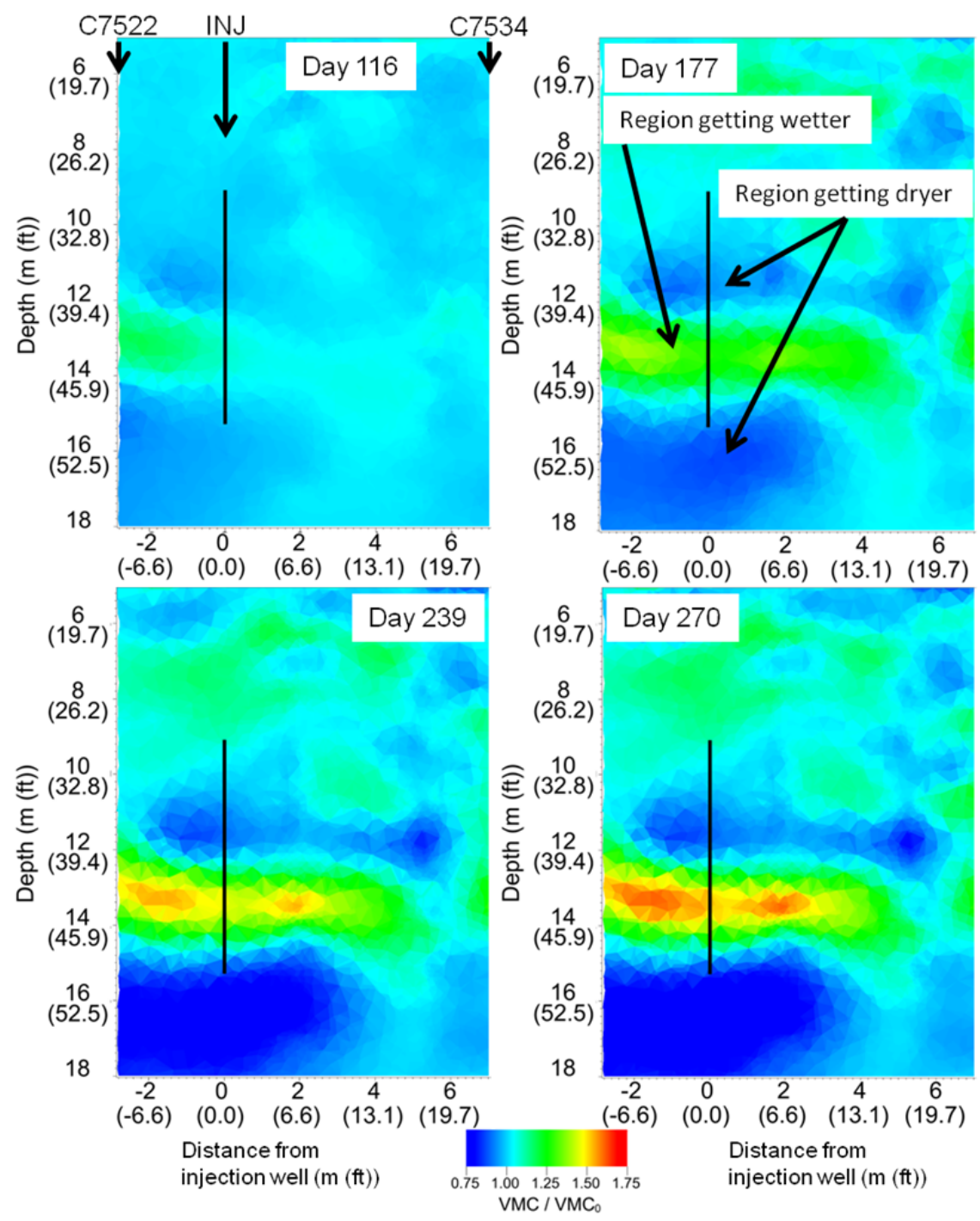

Figure 4.19. Ratio of Volumetric Moisture Content (VMC) to the Volumetric Moisture Content at the End of Active Desiccation $\left(\mathrm{VMC}_{0}\right)$ Over Time along the Axis between the Injection and Extraction Wells from Cross-Hole Electrical Resistivity Tomography (Truex et al. 2012a). ERT data are from sensors at locations C7522-C7534 through day 270 of the postdesiccation period (Figure 3.6). 

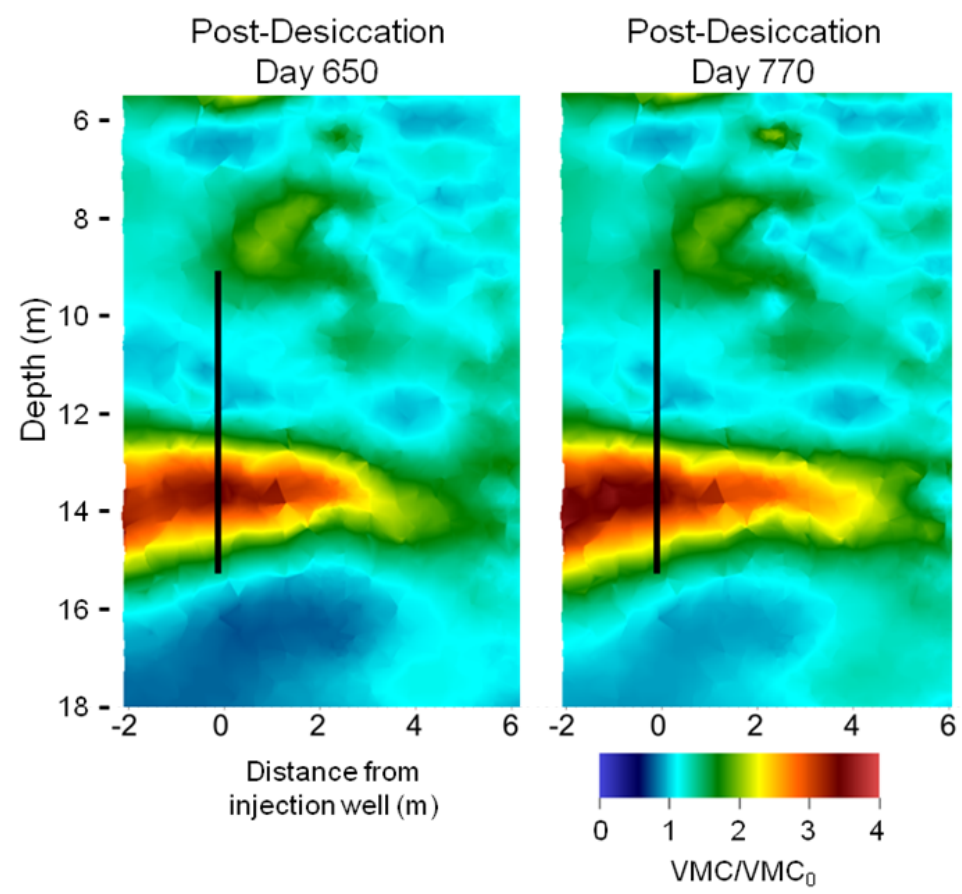

Figure 4.20. Ratio of Volumetric Moisture Content (VMC) to the Volumetric Moisture Content at the End of Active Desiccation $\left(\mathrm{VMC}_{0}\right)$ Over Time along the Axis between the Injection and Extraction Wells from Cross-Hole Electrical Resistivity Tomography. ERT data are from sensors at locations C7522-C7534 for days 650 and 770 of the post-desiccation period (Figure 3.6).

\subsection{Post-Desiccation Monitoring Data Assessment}

Desiccation is intended to help meet remediation goals by slowing the movement of contaminated moisture through the vadose zone and thereby reducing the flux of contaminants into the groundwater. The rate at which moisture returns to the desiccated zone, here termed the rewetting rate, is important in the overall long-term performance of desiccation as part of a remedy.

\subsubsection{Previous Assessment of Rewetting}

Rewetting phenomena and rates have been previously studied through laboratory and modeling efforts. Laboratory data quantifying the rewetting process was collected and reported by Truex et al. (2011). Key conclusions were that vapor-phase rewetting can occur but rewets the desiccated zone only to a small extent, essentially to a level below the residual moisture content. Rewetting by aqueous transport occurs consistent with standard hydraulic phenomena such that desiccating to very low moisture content and creating very low aqueous phase hydraulic conductivity conditions leads to low rates of aqueous transport rewetting.

Previous modeling efforts (Truex et al. 2012a) concluded that the rate of rewetting is a function of the porous media properties of both the desiccated zone and the subsurface surrounding this zone, and the moisture content distribution at the end of desiccation. After desiccation, the moisture content 
distribution in the target zone will trend back toward the equilibrium moisture conditions for the porous media properties. Vapor-phase rewetting will occur, but has a negligible impact on the overall rewetting process. Advective rewetting in the aqueous phase strongly depends on the porous media permeability within and surrounding the desiccated zone and the total thickness of the desiccated zone.

\subsubsection{Assessment of Field Test Rewetting Data}

Rewetting has occurred to varying degrees in different locations at the field test site within the 2-year monitoring period after the end of active desiccation. This type of mixed response was expected because of variations in the thickness of the desiccated zones, differences in the moisture conditions in zones bordering the desiccated zones, and differences in the extent of moisture content reduction. These factors, along with the properties of the porous media, affect the rate of rewetting.

Figure 4.12, showing post-desiccation neutron moisture data for monitoring location C7529, provides an example of the variations in rewetting response related to the variations in the thickness of the desiccated zones, differences in the moisture conditions in zones bordering the desiccated zones, and differences in the extent of moisture content reduction. At the $\sim 13-\mathrm{m}$ bgs depth, where moderate reductions in moisture content occurred during desiccation, moisture content over the 2-year monitoring period has increased back to near pre-desiccation moisture content conditions. This relatively thin depth interval is surrounded above and below by zones of relatively high moisture content. In contrast, there is a much thicker desiccated zone where moisture content was reduced to very low levels from about $14 \mathrm{~m}$ bgs to about $16 \mathrm{~m}$ bgs. In the lower portion of this thick desiccated zone, rewetting has been negligible. Moisture content below the desiccated zone is also relatively low such that, in addition to the low aqueous-phase permeability created by significant drying, there is a relatively small driving force for advective rewetting from below. At the upper portion of this thick desiccated zone, more rewetting has occurred over the 2-year monitoring period. Above the desiccated zone, there are relatively high moisture conditions, and therefore a higher driving force for advective rewetting.

3D STOMP (White and Oostrom 2006) simulations were conducted investigating the rewetting phenomena of the desiccated zone at $44-55 \mathrm{ft}$ bgs. These results are presented in feet below ground surface because the root data for the neutron moisture probe are collected in feet below ground surface. As a result of desiccation, water content levels in this zone were reduced from approximately 0.08 to $<0.01 \mathrm{~m}^{3} / \mathrm{m}^{3}$ at the $\mathrm{C} 7527$ (Figure 4.11) and C7529 (Figure 4.12) locations. At other locations farther away from the injection well, desiccation clearly occurred (e.g., Figure 4.9, Figure 4.10, and Figure 4.13) but not to the extent observed at C7527 and C7529. The 3D simulations included the wetter zones between 40 and $44 \mathrm{ft}$ bgs and were completed with reasonable estimates of hydraulic conductivities and retention parameters for the various sediments (Carsel and Parrish 1988). The simulations showed that under these conditions rewetting occurs from the top downwards in the desiccated zone, as observed in the field (e.g., Figure 4.12), but to supply the water for the rewetting, the wetter zones between 40 to $44 \mathrm{ft}$ bgs drained to almost residual moisture content levels. The latter result is not consistent with field observations because the water content in these wetter layers remained almost constant during the rewetting period. In addition, rewetting of the desiccated zone was predicted to be much slower than the field observations indicate. A sensitivity analysis using reasonable ranges of hydraulic properties did not produce meaningful improvements of the 3D predictions. 
Although the observed rewetting process could not satisfactorily be simulated using a 3D approach, a numerical analysis was conducted to investigate the contribution from water vapor and from horizontal advective water migration from the non-desiccated $44-55 \mathrm{ft} \mathrm{bgs}$ zone towards the desiccation zone. The water vapor movement into the desiccation zone was relatively small. Assuming water vapor diffusive transport into a fully desiccated zone with a radius of $10 \mathrm{ft}$, average volumetric water contents would only increase by $<0.0005 \mathrm{~m}^{3} / \mathrm{m}^{3}$. Horizontal advective rewetting from the non-desiccated $44-55-\mathrm{ft}$ bgs zone was investigated using a 10-ft desiccated zone with desiccated and non-desiccated zone volumetric water contents according to the values shown in Figure 4.11 for C7527. The moisture contents on the left side of the domain represented the moisture content distribution at the end of active desiccation. The moisture contents on the right side of the domain represented the moisture content distribution before desiccation (base). The properties of sand sediments, as described by Carsel and Parrish (1988), were used for this simulation. The initial conditions of this hypothetical example are shown in Figure 4.21a. Over time, water migrates into the previously desiccated zone as shown in Figure $4.21 \mathrm{~b}$ and Figure $4.21 \mathrm{c}$ after 770 days and 10 years, respectively. The simulation shows that in the first 770 days, water migration affects the volumetric water contents over a range of about $1.5 \mathrm{ft}$. Over the next 8 years, the rewetting considerably slows down as a result of the reduced water pressure gradient and only minimal additional movement is observed. The simulated horizontal rewetting process shows water migration from the outside inwards and over relatively small distances, meaning that rewetting in the field would first occur at the locations farther away from the injection well. Field observations (e.g., Figure 4.11 and Figure 4.12) show that rewetting simultaneously takes place at all locations, indicating that horizontal migration is an unlikely rewetting mechanism.

Having established that water vapor transport and horizontal water migration likely only play minor roles in the observed rewetting patterns, an analysis of water mass balances was conducted to demonstrate that the observed rewetting at the various locations can reasonably be explained by vertical migration. To this end, the neutron probe data were used to compute rewetted volume per square meter of lateral extent at five locations (Figure 4.22). This figure shows that the rewetting rate has decreased over time at most locations. For location $\mathrm{C} 7527$, the average rewetting rate (in $\mathrm{L} /\left(\mathrm{m}^{2}\right.$ day)) was used as a boundary condition for a one-dimensional rewetting simulation over the 44-55-ft desiccated bgs zone. The water infiltration results for this example, shown in Figure 4.23, indicate that the simulated rewetting follows a pattern similar to what was observed in the field (Figure 4.11), although the simulated infiltration fronts are somewhat sharper. In addition to the previous finding that horizontal migration is not sufficient to explain the observed rewetting, the simulation results in Figure 4.23 also support the notion that the water that has rewetted the desiccated zone likely has to originate from wetter sediments above this zone. As discussed above, the high moisture zone present at 40-44 ft bgs above the desiccated zone would need to be substantially drained to provide sufficient water for the observed infiltration. However, if the water for infiltration to the desiccated zone originated from a thicker portion of the vadose zone, smaller moisture content changes would be needed to supply sufficient water. While the pattern of moisture content above the desiccated zone does not indicate this type of moisture content reduction (e.g., Figure 4.11), qualitatively, the GPR and ERT data do show decreases in moisture content over large distances and redistribution to the desiccated zones (Figure 4.16, Figure 4.19, and Figure 4.20). 


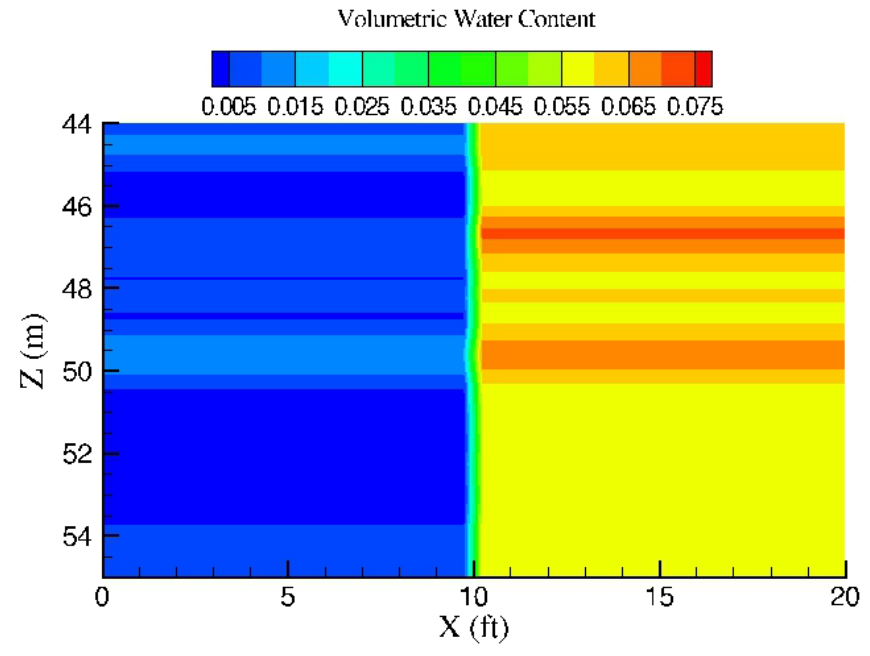

(a)

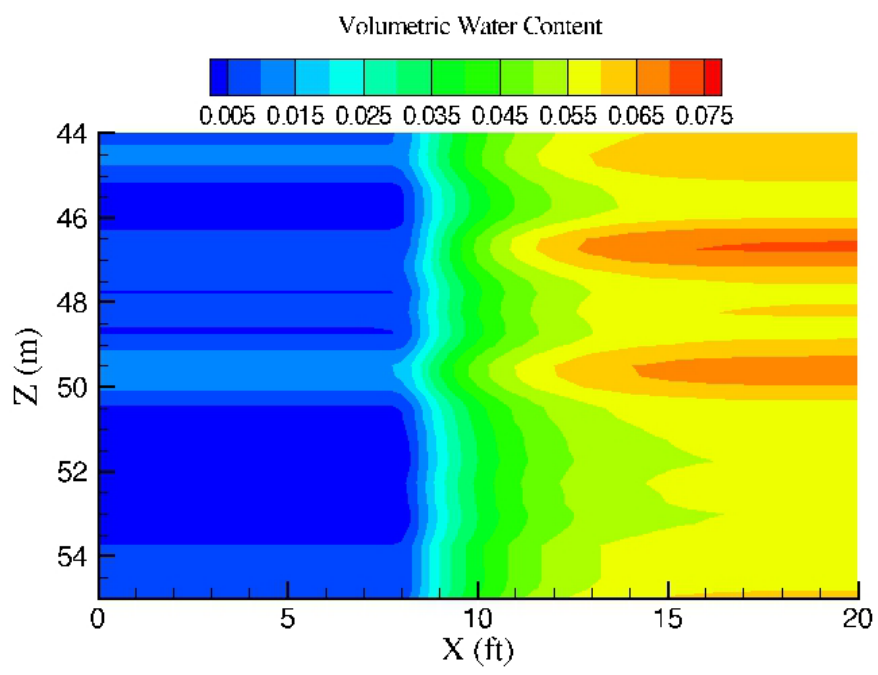

(b)

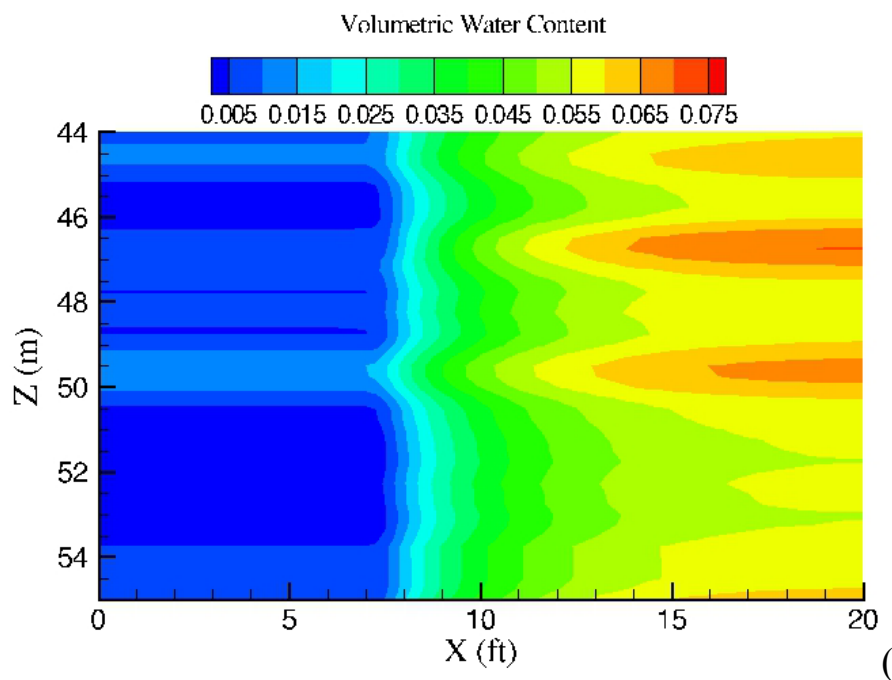

(c)

Figure 4.21. Horizontal Rewetting of the 44-55-ft bgs Desiccated Zone Excluding Water Supply from above $44 \mathrm{ft}$ bgs at (a) 0, (b) 770 Days, and (c) 10 Years after Desiccation Ceased 


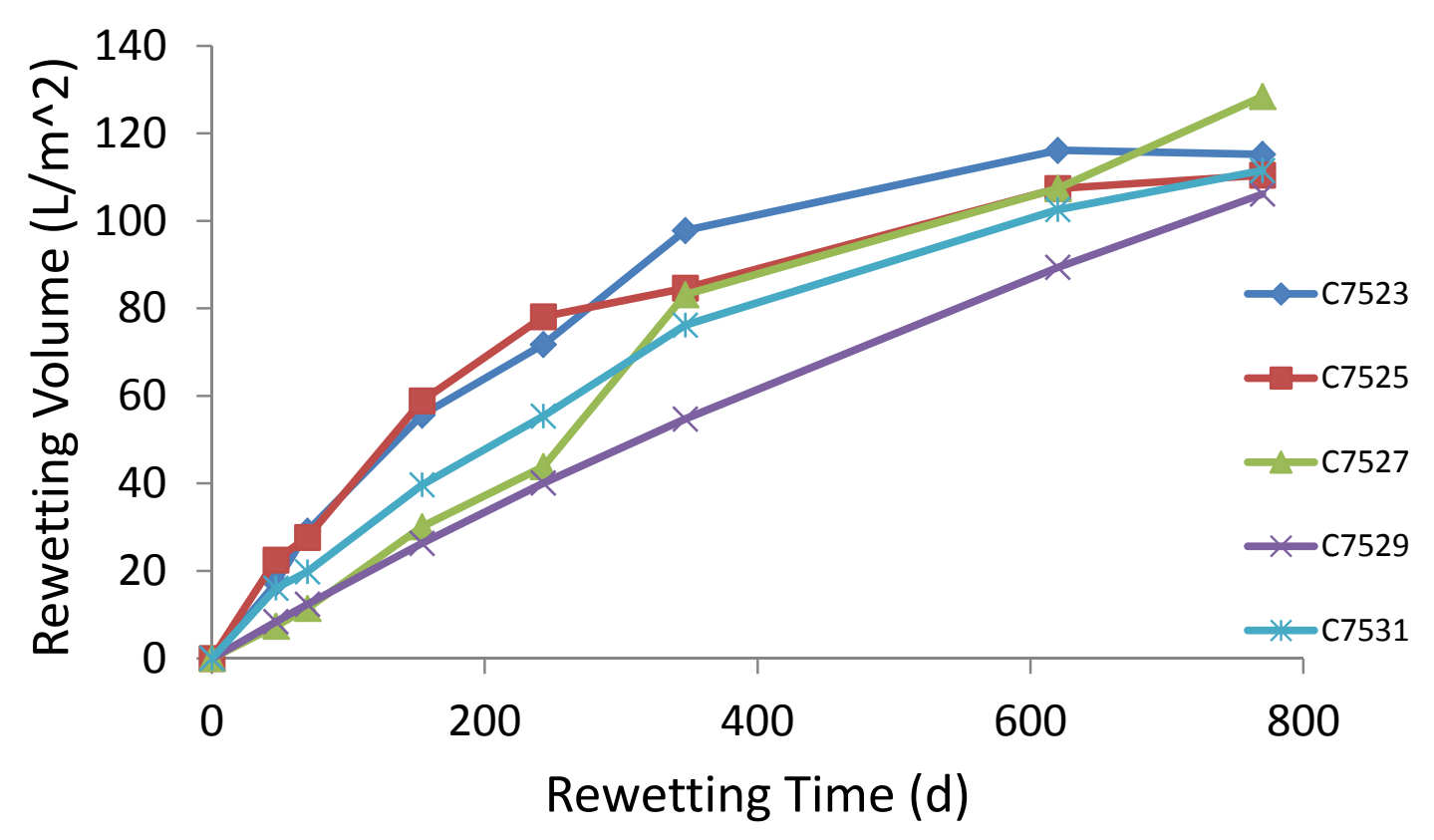

Figure 4.22. Rewetting Volume $\left(\mathrm{L} / \mathrm{m}^{2}\right)$ Estimates as a Function of Rewetting Time. The volume estimates are computed from the neutron moisture probe response data.

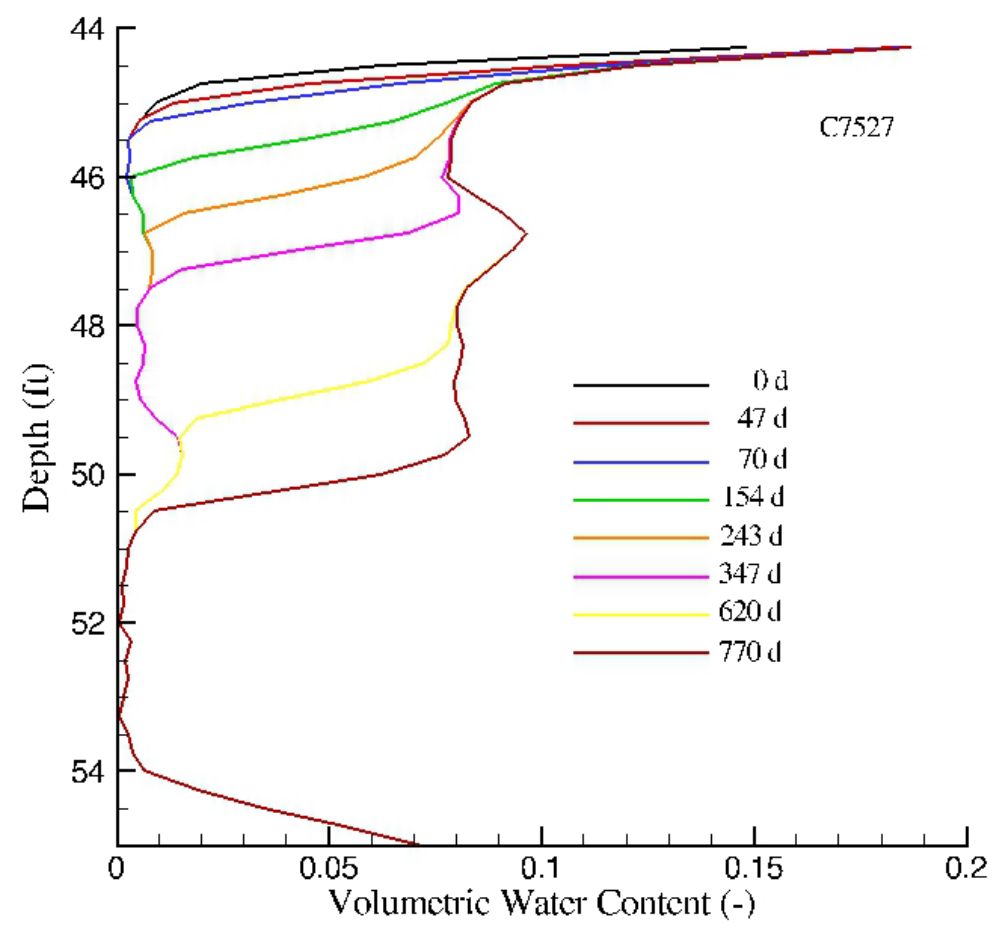

Figure 4.23. Simulated Rewetting at Location C7527 as a Function of Time as a Result of Water Injection over 770 Days at $44 \mathrm{ft}$ bgs with an Average Rate Computed from Figure 4.22 


\subsection{Conclusions}

A field test of desiccation is being conducted at the Hanford Site 200-BC-1 Operable Unit. Desiccation technology relies on removal of water from a portion of the subsurface such that the resultant low moisture conditions inhibit downward movement of water and dissolved contaminants. Previously, a field test report (Truex et al. 2012a) was prepared describing the active desiccation portion of the test and initial post-desiccation monitoring data. Additional monitoring data have been collected at the field test site during the post-desiccation period and are described herein. This is an interim report including about 2 years of post-desiccation monitoring data. The field test plan (DOE 2010b) includes a total of 5 years of post-desiccation monitoring.

The treatability test is being conducted to provide information about desiccation that is intended for use in subsequent feasibility studies for waste sites with inorganic and radionuclide contaminants in the deep vadose zone. The active desiccation portion of the field test occurred over a duration of 164 days, ending on June 30, 2011 (Truex et al. 2012a). The injection and extraction wells were 12-m apart with multiple monitored locations surrounding the injection well. A clustered monitoring approach was used in the test whereby a borehole (sensor borehole) containing sensors, gas-sampling ports, and electrical resistance tomography electrodes was placed nominally adjacent to a cased, unscreened well (logging well) that was used to conduct neutron moisture logging and for application of cross-hole GPR. Monitoring with the in situ sensors and geophysical techniques has been continued during the postdesiccation (rewetting) phase of the test.

Over time, the rate of moisture rewetting of the desiccated zones is a function of the hydraulic gradient, water relative permeability, and porous media unsaturated flow properties. Rewetting data since the end of active desiccation are consistent with expectations based on related laboratory data and numerical simulation analyses. Analysis of the data demonstrate that water advection from relatively wetter zones to dryer zones has occurred. For the zone of most extensive desiccation, nominally between $14 \mathrm{~m}$ and $16 \mathrm{~m}$ bgs, water advection has occurred primarily vertically downward from the moister lowerpermeability sediments shallower than $14 \mathrm{~m}$ bgs that were not significantly dried during desiccation operations. At many locations, a substantial portion of the water removed by desiccation has returned to the desiccation zone over the 2-year rewetting monitoring period. This relatively rapid rewetting was expected based on the moisture conditions within and adjacent to these locations. Rewetting rate data show an initial period of a relatively linear rewetting rate followed by a slowing of the rate as the moisture content approaches local hydraulic equilibrium conditions. In the monitored zones showing the thickest vertical intervals of desiccation, rewetting increased moisture content in the shallow portion of the desiccated zone, but other portions remained dry. To date, the rewetting data are consistent with expectations for desiccation test performance based on laboratory and numerical simulations. These data are important to provide confidence in the design process to scale-up desiccation from the small test-site scale to a larger scale with sufficient capacity to maintain dry conditions over long periods of time and help mitigate contaminant flux to groundwater.

At the field test site the injection well straddled low- and high-permeability sediments. Over the relatively short duration of active desiccation, the higher-permeability sediments were predominantly desiccated near the injection well. However, the moisture content of thick lower-permeability zones was not significantly reduced. Thus, for rewetting, the lower-permeability zones at the test site provide a source of water to rewet the desiccated zones. As described in the previous field test report 
(Truex et al. 2012a), full-scale desiccation as part of a remedy would seek to desiccate thick zones as part of meeting performance goals. In addition, sequential application of desiccation and rewetting periods can lead to a more robust desiccated zone by decreasing the moisture in lower-permeability zones where direct dry gas injection is difficult. However, at the test site, the presence of the moisture source in lowpermeability zones adjacent to the desiccated zones has provided a condition where field-scale rewetting rates can be measured within the time frame of a treatability test and provide valuable confirmation of rewetting processes. With continued monitoring to evaluate the rewetting of the thicker desiccated zones at the site, a robust data set will be available to support evaluation of desiccation performance in support of future feasibility studies. 


\subsection{References}

Archie GE. 1942. "The Electrical Resistivity Log as an Aid in Determining Some Reservoir Characteristics." Petroleum Transactions of AIME 146:54-62.

Bilskie J, R Clawson, and J Ritter. 2007. "Calibration of Heat Pulse Sensors for Soil Water Matric Potential.” In Annual Meetings Abstracts [CD] ASA, CSSA, and SSSA, Madison, Wisconsin.

Binley A, G Cassiani, R Middleton, and P Winship. 2002. "Vadose Zone Model Parameterisation Using Cross-Borehole Radar and Resistivity Imaging." Journal of Hydrology 267(3-4):147-159.

Carsel RF and RS Parrish. 1988. "Developing Joint Probability Distributions of Soil Water Retention Characteristics." Water Resources Research 24(5):755-769.

Corbin RA, BC Simpson, MJ Anderson, WF Danielson III, JG Field, TE Jones, and CT Kincaid. 2005. Hanford Soil Inventory Model Rev. 1. RPP-26744, Rev. 0, CH2M HILL Hanford Group, Inc., Richland Washington.

Daily W and E Owen. 1991. "Cross-Borehole Resistivity Tomography.” Geophysics 56:1228-1235.

Day-Lewis FD, JM Harris, and SM Gorelick. 2002. "Time-lapse Inversion of Crosswell Radar Data." Geophysics 67:1740-1752.

Dresel PE, DM Wellman, KJ Cantrell, and MJ Truex. 2011. "Review: Technical and Policy Challenges in Deep Vadose Zone Remediation of Metals and Radionuclides." Environmental Science \& Technology 45(10):4207-4216.

DOE/RL (U.S. Department of Energy Richland Office). 2008a. Deep Vadose Zone Treatability Test Plan for the Hanford Central Plateau. DOE/RL-2007-56, Rev. 0, Richland, Washington.

DOE/RL (U.S. Department of Energy Richland Operations Office). 2008b. Sampling and Analysis Plan for Characterization of the Soil Desiccation Pilot Test Site. DOE/RL-2008-67, Rev. 0, Richland, Washington.

DOE/RL (U.S. Department of Energy Richland Operations Office). 2010a. Characterization of the Soil Desiccation Pilot Test Site. DOE/RL-2009-119, Rev. 0, Richland, Washington.

DOE/RL (U.S. Department of Energy Richland Operations Office). 2010b. Field Test Plan for the Soil Desiccation Pilot Test. DOE/RL-2010-04, Rev. 0, Richland, Washington.

Evett SR. 2005. International Soil Moisture Sensor Comparison. In Irrigation Insights No. 1, Second Edition, Soil Water Monitoring. P Charlesworth (ed.), pp. 68-71, Land \& Water Australia, Braddon, Australia.

Flint AL, GS Campbell, KM Ellett, and C Calissendorff. 2002. "Calibration and Temperature Correction of Heat Dissipation Matric Potential Sensors.” Soil Science Society of America Journal 66:1439-1445. 
Hubbard SS, JE Peterson, EL Majer, PT Zawislanski, J Roberts, KH Williams, and F Wobber. 1997. "Estimation of Permeable Pathways and Water Content Using Tomographic Radar Data." The Leading Edge of Exploration 16(11):1623-1628.

Huisman JA, C Sperl, W Bouten, and JM Verstraten. 2001. "Soil Water Content Measurements at Different Scales: Accuracy of Time Domain Reflectometry and Ground-Penetrating Radar." Journal of Hydrology 245:48-58.

Jackson MJ and DR Tweeton. 1994. MIGRATOM - Geophysical Tomography Using Wavefront Migration and Fuzzy Constraints. Bureau of Mines Report of Investigations 9497, Pittsburgh, Pennsylvania.

Johnson TC, RJ Versteeg, A Ward, FD Day-Lewis, and A Revil. 2010. “Improved Hydrogeophysical Characterization and Monitoring Through Parallel Modeling and Inversion of Time-Domain Resistivity and Induced Polarization Data." Geophysics 75(4):WA27-WA41.

Oostrom M, TW Wietsma, JH Dane, MJ Truex, and AL Ward. 2009. "Desiccation of Unsaturated Porous Media: Intermediate-Scale Experiments and Numerical Simulation." Vadose Zone Journal $8: 643-650$.

Oostrom M, GD Tartakovsky, TW Wietsma, MJ Truex, and JH Dane. 2011. "Determination of Water Saturation in Relatively Dry and Desiccated Porous Media Using Gas-Phase Partitioning Tracer Tests." Vadose Zone Journal 10:1-8; doi:10.2136/vzj2010.0101.

Oostrom M, TW Wietsma, CE Strickland, VL Freedman, and MJ Truex. 2012a. "Instrument Testing During Desiccation and Rewetting at the Intermediate Laboratory Scale." Vadose Zone Journal doi:10.2136/vzj2011.0089.

Oostrom, M., V.L. Freedman, T.W. Wietsma, and M.J. Truex. 2012b. "Effects of porous medium heterogeneity on vadose zone desiccation: Intermediate-scale laboratory experiments and simulations." Vadose Zone Journal doi:10.2136/vzj2011.0168.

Serne RJ, AL Ward, W Um, BN Bjornstad, DF Rucker, DC Lanigan, and MW Benecke. 2009. Electrical Resistivity Correlation to Vadose Zone Sediment and Pore-Water Composition for the BC Cribs and Trenches Area. PNNL-17821, Pacific Northwest National Laboratory, Richland, Washington.

Slater LD and DP Lesmes. 2002. "Electrical-Hydraulic Relationships Observed for Unconsolidated Sediments. Water Resources Research 38:1213-1225.

Topp GC and PA (Ty) Ferré. 2002. "Water Content." In Methods of Soil Analysis Part 4, Physical Methods, SSSA Book Series No. 5, JH Dane and GC Topp (eds.), Section 3.1, pp. 417-545, Soil Science Society of America, Inc., Madison, Wisconsin.

Truex MJ, M Oostrom, VL Freedman, CE Strickland, and AL Ward. 2011. Laboratory and Modeling Evaluations in Support of Field Testing for Desiccation at the Hanford Site. PNNL-20146, Pacific Northwest National Laboratory, Richland, Washington. 
Truex MJ, M Oostrom, CE Strickland, TC Johnson, VL Freedman, CD Johnson, WJ Greenwood, AL Ward, RE Clayton, MJ Lindberg, JE Peterson, SS Hubbard, GB Chronister, and MW Benecke. 2012a. Deep Vadose Zone Treatability Test for the Hanford Central Plateau: Soil Desiccation Pilot Test Results. PNNL-21369, Pacific Northwest National Laboratory, Richland, Washington.

Truex MJ, M Oostrom, CE Strickland, GB Chronister, MW Benecke, and CD Johnson. 2012b. "FieldScale Assessment of Desiccation Implementation for Deep Vadose Zone Contaminants." Vadose Zone Journal doi:10.2136/vzj2011.0144

Truex MJ, TC Johnson, CE Strickland, JE Peterson, and SS Hubbard. 2013. "Monitoring Vadose Zone Desiccation with Geophysical Methods.” Vadose Zone Journal doi:10.2136/vzj2012.0147

Um W, RJ Serne, MJ Truex, AL Ward, MM Valenta, CF Brown, C Iovin, KN Geiszler, IV Kutnyakov, ET Clayton, H-S Chang, SR Baum, and DM Smith. 2009. Characterization of Sediments from the Soil Desiccation Pilot Test (SDPT) Site in the BC Cribs and Trenches Area. PNNL-18800, Pacific Northwest National Laboratory, Richland, Washington.

Van Overmeeren R, S Sariowan, and J Geherls. 1997. “Ground Penetrating Radar for Determining Volumetric Soil Water Content: Results of Comparative Measurements at Two Test Sites." Journal of Hydrology 197:316-338.

Ward AL, GW Gee, ZF Zhang, and JM Keller. 2004. Vadose Zone Contaminant Fate and Transport Analysis for the 216-B-26 Trench. PNNL-14907, Pacific Northwest National Laboratory, Richland, Washington.

Ward AL, M Oostrom, and DH Bacon. 2008. Experimental and Numerical Investigations of Soil Desiccation for Vadose Zone Remediation: Report for Fiscal Year 2007. PNNL-17274, Pacific Northwest National Laboratory, Richland, Washington.

White MD and M Oostrom. 2006. STOMP Subsurface Transport Over Multiple Phases, Version 4.0, User's Guide. PNNL-15782, Pacific Northwest National Laboratory, Richland, Washington. 


\section{Distribution}

No. of

Copies

DOE Richland Operations Office

JG Morse

CH2M HILL Plateau Remediation Company

GB Chronister
No. of

Copies

Pacific Northwest National Laboratory

RE Clayton PDF

CD Johnson PDF

TC Johnson PDF

M Oostrom PDF

CE Strickland PDF

MJ Truex PDF

DM Wellman PDF

Information Release Office PDF

All distribution will be made electronically. 


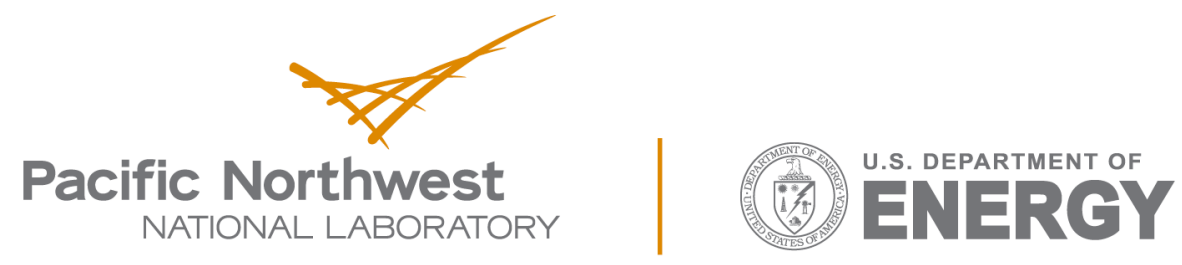

Proudly Operated by Battelle Since 1965

902 Battelle Boulevard

P.O. Box 999

Richland, WA 99352

1-888-375-PNNL (7665)

www.pnnl.gov 